\title{
MUDANÇAS NA CIRCULAÇÃO ATMOSFÉRICA SOBRE A AMÉRICA DO SUL PARA CENÁRIOS FUTUROS DE CLIMA PROJETADOS PELOS MODELOS GLOBAIS DO IPCC AR4
}

\author{
MARÍA C. VALVERDE E JOSÉ A. MARENGO \\ Centro de Previsão do Tempo e Estudos Climáticos, Instituto Nacional de Pesquisas Espaciais \\ (CPTEC/INPE), Cachoeira Paulista, SP, Brasil.
}

maria.valverde@cptec.inpe.br, jose.marengo@cptec.inpe.br

Recebido Dezembro 2007 - Aceito Setembro 2009

\begin{abstract}
RESUMO
Neste trabalho são analisadas as mudanças no padrão de circulação que possam vir a acontecer no clima da América do Sul (AS), como conseqüência do aumento nas concentrações dos gases de efeito estufa. Para isto utilizam-se cinco modelos globais do IPCC AR4 (CCCMA, GFDL, HadCM3, MIROC e GISS), para o clima do século XX (1961-1990 - 20C3M) e para o cenário futuro SRES_A2 (2011-2100). As características em comum que os modelos apresentaram (a exceção do MIROC) para as três climatologias futuras (2011-2040, 2041-2070 e 2071-2100), principalmente, no verão e na primavera, foram o deslocamento da baixa continental (associada à baixa do Chaco) para o sudoeste da sua posição climatológica (1961-1990), e da Alta da Bolívia para o noroeste.

Além disso, os cinco modelos simularam, para o clima presente, uma Alta do Pacífico Sul (APS) menos intensa em relação à Reanálise do NCEP, sugerindo menor subsidência sobre a sua região de atuação. Para cenários futuros os modelos GISS e HadCM3 simularam a APS menos intensa. Por outro lado, para a alta do Atlântico Sul, não existiu um consenso nos modelos. Em geral foi simulada mais intensa (a exceção do GISS), sobretudo no outono e no inverno.

O modelo HadCM3 simulou a circulação de verão e primavera mais próxima à Reanálise, com uma ZCAS melhor definida, e uma área menor de anomalias negativas de chuva sobre a Amazônia, em relação aos outros modelos. Já para o cenário futuro este modelo modificou seu padrão de chuvas, e anomalias positivas, sobre a costa norte do Peru e Equador, e negativas sobre o Nordeste e leste da Amazônia, foram observadas, associadas a uma APS enfraquecida e deslocada para o sul, o que reforçou a ZCIT do Pacífico sobre $5^{\circ} \mathrm{S}$. Uma diminuição da convergência de umidade sobre a Amazônia também foi observada.

Palavras-Chave: Mudanças Climáticas, Modelos do IPCC AR4, Padrão de Circulação, Cenários futuros.
\end{abstract}

\footnotetext{
ABSTRACT: CHANGES IN THE ATMOSPHERIC CIRCULATION PATTERN OVER SOUTH AMERICA IN FUTURE CLIMATE SCENARIOS DERIVED FROM THE IPCC AR4 MODEL CLIMATE SIMULATIONS

In this paper changes in the atmospheric circulation that may occur in the South America (SA) as a consequence of climate change were studied for various emission scenarios. Five global models from IPCC AR4 (CCCMA, GFDL, HadCM3, MIROC and GISS) are used, for 1961-1990 (present climate) from the 20C3M model run, and for 2011-2100 for the SRES A2 high emission scenario. For the future, (2011-2040, 2041-2070 and 2071-2100 time periods), in most of the models (except the MIROC), the thermal continental low (Chaco low) is shifted to the southwest while the Bolivian High is northwest shifted during in the summer and spring. All the models show, for present climate simulation a weak subtropical southeast Pacific anticyclone (SPA), which would induce a reduction atmospheric subsidence. When the anticyclone is shifted southward, it would be linked with a stronger and more southward Pacific ITCZ. For the future climate, only two models (HadCM3 and GISS)
} 
show a weaker SPA as compared to the present. On the other hand, the subtropical southwest Atlantic anticyclone (SAA) seems to be more intense during fall and winter in almost all models (with the exception of the GISS model).

Among the different models, the HadCM3 simulates the summer and spring circulation close to NCEP Reanalysis. This model does exhibit a relatively well simulated SACZ, contributing with a decrease of precipitation over Amazon. Moreover, for the future scenarios the HadCM3 model shows changes in rainfall patterns, with positive anomalies over the West Coast of Peru and Equator and negative anomalies over Northeast of Brazil, and Eastern of Amazon, linked to weaker and southward shifted South Pacific High, enforcing the ITCZ over $5^{\circ} \mathrm{S}$, as a consequence of a decrease of the moisture convergence over Amazon.

Keywords: Climatic changes, IPCC AR4 models, Circulation Pattern, future scenarios.

\section{INTRODUÇÃO}

Segundo o Quarto Relatório de Avaliação do Grupo de Trabalho I do "Intergovernmental Panel on Climate Change" (IPCC AR4) divulgado em fevereiro de 2007, as evidências científicas sugerem que é muito provável, que a maior parte do aumento na temperatura global média observada no planeta, desde meados do século XX possa ser explicada pelo aumento nas concentrações de gases de efeito estufa (IPCC, 2007a), associada às atividades antrópicas. Neste contexto, observam-se mudanças significativas no clima e extremos climáticos, e os seus impactos nos diversos sistemas físicos e biológicos ocasionados pela elevação da temperatura do ar como apresentados no relatório do Grupo de Trabalho II (IPCC, 2007a).

No clima estas mudanças em regimes de extremos de curto e longo prazo, poderiam ser semelhantes aos extremos de chuva e temperatura que se vêm registrando na América do Sul. Podem-se citar as secas de 2005 na Amazônia (Marengo et al., 2007a) e de 2006 no sul do Brasil (Marengo et al., 2007b), o furacão Catarina de 2004 no sul do Brasil (Pezza e Simmond, 2005), as enchentes abundantes no verão de 2007 sobre o setor leste da Bolívia (SENAMHI, 2007), e as ondas de frio na Argentina e Chile no inverno de 2007 (SMN, 2007). Todos estes eventos causaram forte impactos nos diferentes ecossistemas, e conseqüentemente na população e na economia regional e nacional.

Para a América Latina, as projeções futuras mostram que até meados do século XXI, os aumentos de temperatura e as reduções de chuva e de vazões de rios poderão levar a uma substituição gradual da floresta tropical por savana no leste da Amazônia, e a vegetação semi-árida tenderá a ser substituída por vegetação de terras áridas (Salazar et al., 2007; IPCC, 2007b).

Os cenários futuros, derivados do "Special Report on Emissions Scenários" (SRES) do IPCC, representam a informação mais atual do que poderá vir a acontecer, numa combinação de desenvolvimento tecnológico, social, demográfico e de emissões de gases de efeito estufa. Quatro linhas evolutivas qualitativas proporcionam quatro conjuntos de cenários denominados "famílias": A1, A2, B1 e B2, onde a família A1 se compõe de três grupos (A1F1, A1B e A1T), sendo que do conjunto total de cenários, levando em consideração a concentração de $\mathrm{CO}_{2}$ (emissões acumulativas em 1990-2100), os cenários A1F1 (2128 GtC) e o B1 (989 GtC) são os mais extremos. $\mathrm{O}$ cenário $\mathrm{A} 1 \mathrm{~F} 1$ enfatiza a utilização intensiva de combustível de origem fóssil, já o B1 visa uma sustentabilidade econômica, social e meio ambiental (Nakicenovic et al., 2000).

Fazendo uma cronologia de trabalhos que têm focado as projeções futuras no clima, principalmente no comportamento do padrão de chuva sobre o Brasil, são citados os mais recentes, aqueles que utilizaram os modelos do terceiro relatório ("Third Assessment Report - IPCC TAR") divulgado em 2001. Marengo (2007b) analisou cinco modelos do IPCC TAR para a região do Brasil, e encontrou para cenários futuros (A2 e B2), que os modelos GFDL, CCCMA e CCSNIER tinham dificuldades em simular a banda chuvosa associada à ZCAS, enquanto que o HadCM3 não. Por outro lado, os modelos CSIRO e GFDL apresentaram vieses secos no sul do Brasil, assim como o HadCM3 no leste da Amazônia. Também encontrou que o HadCM3 manteve a ZCAS intensa no cenário B2, porém, reduz a chuva sobre a Amazônia e Nordeste no cenário A2. Valverde e Marengo (2006) quantificaram em porcentagem o déficit e superávit da chuva em cinco modelos do IPCC TAR, e encontraram que enquanto o HadCM3 reduzia a chuva no Nordeste em até 64\% abaixo de sua climatologia (1961-1990), o GFDL simulava um aumento de até $152 \%$ para o período de 2071-2100. Sobre a Bacia da Prata, tanto o HadCM3 como o GFDL mostraram aumentos das chuvas em até $15 \%$ e 17 \%, respectivamente. Sobre a Amazônia o GFDL e o CSIRO mostraram excessos de chuva, enquanto que o HadCM3 apresentou diminuição em até $15 \%$ para o período de 2071 2100.

No recente relatório do IPCC AR4, divulgado em 2007, foram utilizados os modelos do IPCC com valores melhorados, em relação às emissões de gases estufa, assim como, informação 
atualizada sobre a reestruturação econômica em todo o mundo, diferentes taxas de crescimento, e tendências de mudanças tecnológicas para os diferentes cenários. Vera et al. (2006) utilizaram seis modelos globais acoplados do IPCC AR4 para o clima presente e cenários futuros (A1B), e identificaram características já encontradas nos modelos do IPCC TAR, tais como as discrepâncias na posição e intensidade das ZCAS, o que se reflete diretamente na quantidade de chuva sobre as bacias da Amazônia e da Prata. Para cenários futuros (2070-2099) os resultados mostraram o aumento da chuva de verão sobre o norte dos Andes e sudeste da AS, e a diminuição desta ao longo do sul dos Andes chilenos e argentinos em todas as estações.

Bombardi e Carvalho (2007) analisaram a variabilidade da Monção da América do Sul e seu impacto sobre o cerrado brasileiro utilizando o modelo MIROC. A variabilidade para o clima do século XX (1981-2000) foi bem representada pelo modelo, porém, para cenários futuros (2061-2080) foram observadas mudanças na probabilidade dos eventos extremos (secos e úmidos) sobre o cerrado, o que indica uma maior exposição da região a possíveis conseqüências do aumento de gases de efeito estufa.

Para a região da Amazônia, Li et al. (2006) avaliaram a precipitação sazonal e anual para o século XXI (2050-2099, cenário A1B), utilizando os modelos do IPCC AR4. Eles encontraram que dos onze modelos analisados, cinco deles (CNRM-CM3, GISS-EH, GISS-ER, IPSL-CM4, e NCARCCSM3) mostravam incrementos na chuva anual, três (GFDLCM2.1, MIROC3.2-MEDRES e UKMO-HadCM3) mostravam um decrescimento das chuvas, e os outros três modelos (INMCM3.0, ECHAM5/MPI-OM e MRI-CGM2.3.2) não mostravam mudanças significativas nas chuvas.

Grimm e Natori (2006) estudaram a variabilidade interanual da precipitação na estação de monção de verão na América do Sul (AS) e sua relação com o ENOS, utilizando o modelo ECHAM5-OM (IPCC AR4) para o clima presente (1961-1990) e para o cenário SRES-A2 (2071-2100). Através da metodologia das funções ortogonais empíricas encontraram que o primeiro modo de variabilidade de precipitação, derivado do

Tabela 1 - Mapa de América do Sul com as áreas de localização dos sistemas de pressão: Alta subtropical do Pacífico Sul (APS), do Pacífico Norte (APN), do Atlântico Norte (AAN), do Atlântico Sul (AAS) e a baixa continental (BC).

\begin{tabular}{|c|c|c|c|}
\hline Modelos & Instituição & Resolução & Período \\
\hline $\begin{array}{c}\text { UKMO_HadCM3 } \\
\text { (HadCM3) }\end{array}$ & $\begin{array}{l}\text { Hadley Centre for Climate Prediction } \\
\text { and Research, Met Office England. }\end{array}$ & $\begin{array}{l}2.5^{\circ} \text { lat. } \times 3.75^{\circ} \text { lon. } \\
(\mathrm{L} 19, \mathrm{~T} 42)\end{array}$ & $1950-2099$ \\
\hline $\begin{array}{l}\text { GFDL-CM2.1 } \\
\text { (GFDL) }\end{array}$ & $\begin{array}{l}\text { Geophysical Fluid Dynamics Laboratory } \\
\text { - NOAA. }\end{array}$ & $\begin{array}{l}2^{\circ} \text { lat. } \times 2.5^{\circ} \text { lon. } \\
\text { (L24) }\end{array}$ & $1961-2100$ \\
\hline $\begin{array}{l}\text { CGCM3.1 } \\
\text { (CCCMA) }\end{array}$ & $\begin{array}{l}\text { Canadian Center for Climate Modeling } \\
\text { and Analysis - Canada }\end{array}$ & $\begin{array}{c}3.75^{\circ} \text { lat } \times 3.75^{\circ} \text { long } \\
\text { (T47) }\end{array}$ & $1900-2100$ \\
\hline $\begin{array}{l}\text { GISS-ER } \\
\text { (GISS) }\end{array}$ & $\begin{array}{l}\text { Goddard Institute for Space Studies } \\
\text { NASA/USA }\end{array}$ & $\begin{array}{l}4^{\circ} \text { lat } \times 5^{\circ} \text { long. } \\
\text { (L15) }\end{array}$ & $1961-2100$ \\
\hline $\begin{array}{c}\text { MIROC3.2 - } \\
\text { medres } \\
\text { (MIROC) }\end{array}$ & $\begin{array}{l}\text { Centre for Climate System Research/ } \\
\text { (CCSR) (Univ. of Tokyo), National } \\
\text { Institute for Environmental Studies/ } \\
\text { (NIES), Frontier Research Center For } \\
\text { Global Change (Japan). }\end{array}$ & $\begin{array}{c}\sim 2.8^{\circ} \text { lat } \times 2.8^{\circ} \text { lon. } \\
(\mathrm{L} 20, \mathrm{~T} 42)\end{array}$ & $1900-2100$ \\
\hline
\end{tabular}


modelo, era associado com o ENOS, tanto na primavera como no verão. Para cenários futuros, esta variabilidade se torna mais fraca (forte) no sudeste (norte) da AS devido a uma redução (aumento das anomalias da TSM) do gradiente latitudinal da TSM nos subtrópicos do Pacífico central leste.

Em relação ao padrão intrasazonal de precipitação, Lin et al. (2006), analisaram oito anos de dados diários de precipitação em 14 modelos do IPCC AR4, do experimento "Climate of the 20th Century Experiment" (20C3m) para determinar tipos de oscilações, em especial, as de Madden-Julian, e foi encontrado que os modelos tiveram dificuldade em representar a variabilidade intrasazonal da convecção tropical, simulando um sinal muito fraco da variância total intrasazonal (2-128 dias) da precipitação. Somente em dois modelos (ECHAM5/MPI-OM e CNRM-CM3) a variância se aproximou ao valor observado.

Um ponto interessante, levantado por diversos autores (Grimm et al., 2006; Breugem et al., 2006; AchutaRao e Sperber, 2006; Guilyardi, 2009), se refere ao fato que os modelos de circulação geral acoplados oceano-atmosfera, como aqueles usados no IPCC AR4, têm dificuldade em representar adequadamente os principais modos de variabilidade de baixafreqüência do sistema oceano-atmosfera, tais como, as oscilações decadal e multi-decadal, além dos modos de variabilidade intrasazonal. Esta dificuldade relaciona-se também com a limitação que os modelos apresentam na simulação do comportamento climático médio da atmosfera (Lin et al., 2004; Breugem et al., 2006; Grimm et al., 2006).
Um trabalho recente que ressaltou as mudanças na intensidade do vento e pressão sobre a costa sudoeste da América do Sul foi desenvolvido por Garreaud e Falvey (2008). O resultado da anomalia média de 15 modelos do IPCC AR4 para o cenário futuro A2 (2071-2100), na primavera e verão, mostrou a intensificação dos ventos do sul ao longo da costa subtropical do Pacífico Sul (jato subtropical costeiro - 15/m/s), como conseqüência de um forte incremento da pressão em superfície, no setor sul, na faixa costeira do Chile, entre $37^{\circ}-41^{\circ} \mathrm{S}$.

Cenários futuros derivados de modelos proporcionam uma estimativa das alterações dos padrões extremos de chuva, sendo também importante a verificação de variáveis dinâmicas para um melhor entendimento dos mecanismos físicos responsáveis pela geração dessas anomalias.

Neste contexto, fazendo uso dos modelos melhorados do IPCC AR4, e considerando que a maioria dos estudos tem enfatizado apenas as análises das anomalias de temperatura e precipitação, este trabalho tem como objetivo avaliar o comportamento da circulação atmosférica associada aos excessos ou diminuição de chuva ao longo do clima presente e futuro, utilizando cinco modelos do IPCC AR4. O conhecimento de como o padrão da circulação atmosférica pode vir a mudar, como conseqüência do aumento acelerado das concentrações de $\mathrm{CO}_{2}$ e outros gases de efeito estufa, proporcionam uma informação que pode servir de base no monitoramento atual dos padrões climáticos, caso alterações semelhantes venham a ser observadas.

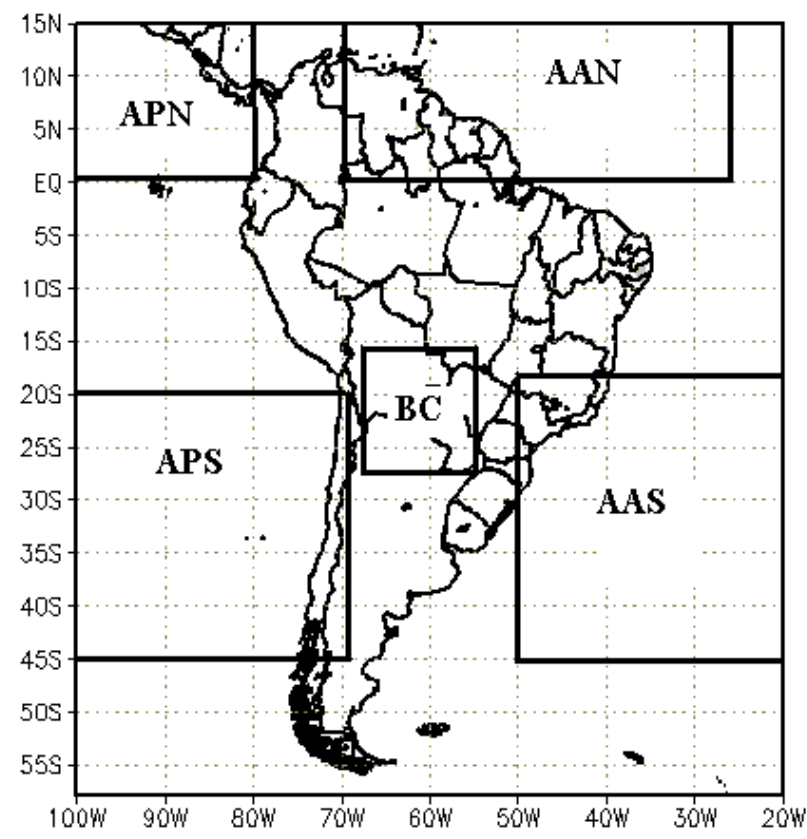

Figura 1 - Mapa de América do Sul com as áreas de localização dos sistemas de pressão: Alta subtropical do Pacífico Sul (APS), do Pacífico Norte (APN), do Atlântico Norte (AAN), do Atlântico Sul (AAS) e a baixa continental (BC). 


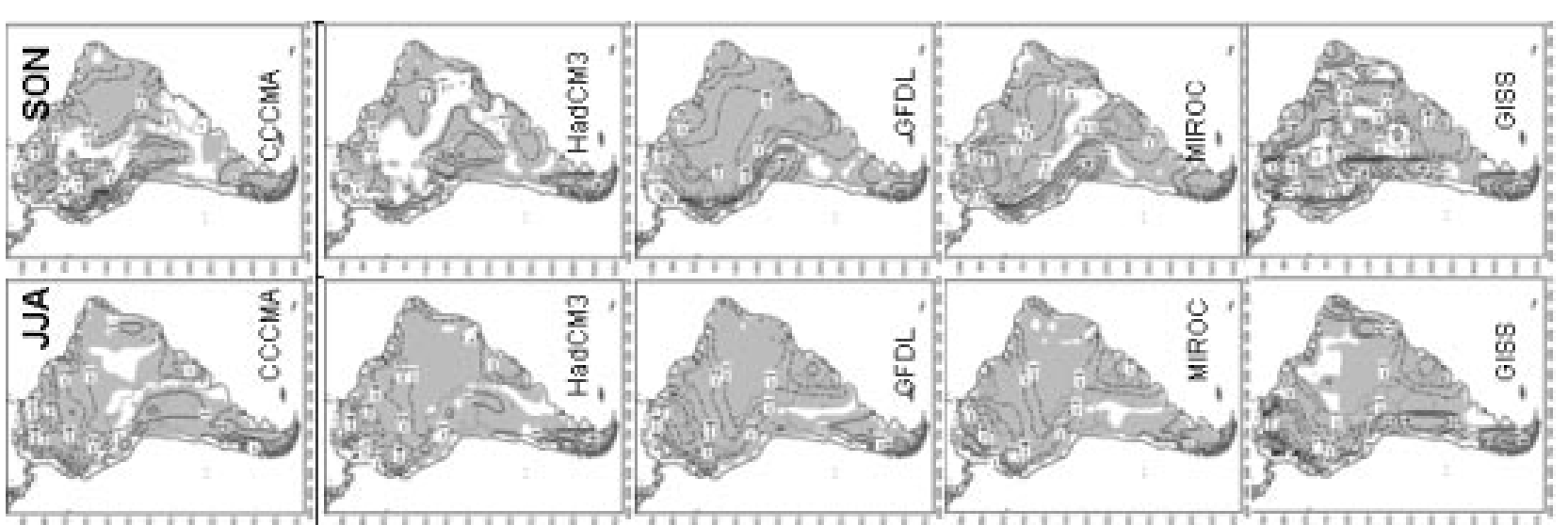

宅 壱
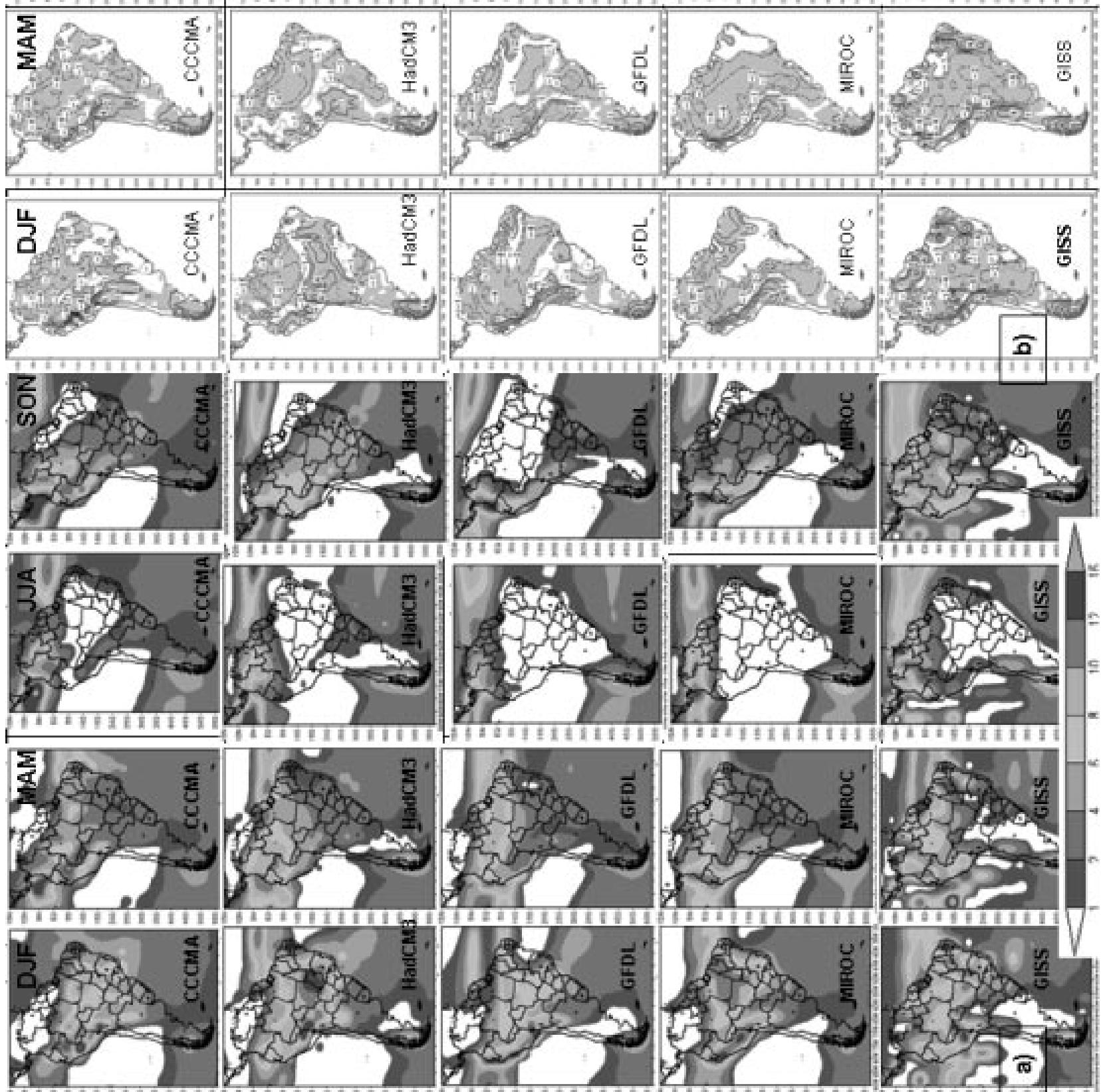

㲾

ฮ

$\ddot{\square}$

过

@

के के

$\frac{6}{0} \frac{\pi}{0}$

¿

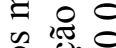

范

อ

(⿶凵

कृ

远 $\frac{\bar{\sigma}}{\pi}$

(c)

胥胥

윰

这

藏

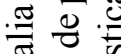

栗

ส

西

$2 \varangle$

형

궁

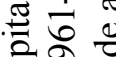

웡 9

芒䨌

$\div$ ?

.

\%

讯

ڤ ڤ

సิ थ

$\sum^{\infty} \mathbb{0}$

N

ฮิ 


\section{DADOS E METODOLOGIA}

\subsection{Dados}

Neste trabalho foram utilizadas as saídas de cinco modelos globais acoplados oceano-atmosfera (CCCMA, GFDL, HadCM3, MIROC e o GISS) do IPCC AR4 (Tabela 1), obtidas do site do "Program for Climate Model Diagnosis and Intercomparison" (PCMDI), para o clima do século XX (20C3m) e cenário futuro (SRES_A2). O experimento 20C3m representa o clima atual com uma mudança temporal da taxa de $\mathrm{CO}_{2}$ atmosférico de $350 \mathrm{ppm}$, para $370 \mathrm{ppm}$ desde 1900 até 2000 . No cenário A2 se descreve um mundo futuro muito heterogêneo onde existirá um crescimento populacional alto e uma menor preocupação em relação ao desenvolvimento econômico rápido. Neste cenário as emissões de gases de efeito estufa se incrementam ao longo do século 21 , onde o $\mathrm{CO}_{2}$ atingirá o valor de 850 ppm em 2100 (Nakicenovic et al., 2000).

Os cinco modelos foram selecionados, pois além de terem sido utilizados no IPCC TAR e disponibilizados pelo IPCC DCC ("Data Distribution Centre") para a comunidade científica, eles mostraram melhoras quanto à resolução, como é o caso dos modelos MIROC/CCR-NIES, que mudou de 5,6 x $5,6^{\circ}$ (TAR) para $2,8^{\circ} \times 2,8^{\circ}$ (AR4), e do modelo GFDL, que melhorou de $4,5^{\circ} \times 7,5^{\circ}$ (TAR) para $2^{\circ} \times 2,25^{\circ}$ (AR4). Por outro lado, o modelo GISS nos diferentes estudos do IPCC TAR e IPCC AR4, mostrou uma tendência a simular muita chuva sobre a Amazônia em relação aos outros modelos (Dai, 2006 e Li et al., 2006), e por isso, a motivação na análise do campo de circulação deste modelo. Finalmente foi utilizado o modelo HadCM3 do Reino Unido, o qual tem sido bastante documentado em estudos de regionalização ou "downscaling" dinâmico na América do Sul, além de existir estudos que indicam, que este modelo representa melhor o padrão de chuva sobre os Trópicos (Dai, 2006; Li et al., 2006).

As principais características de cada modelo são mostradas na Tabela 1 e detalhadas no seguinte endereço: http://www-pcmdi.llnl.gov/ipcc/about_ipcc.php).

Também foram utilizados dados de precipitação e temperatura mensal do "Climatic Research Unit" (CRU) (New et al., 1999), com resolução de 0,5 lat x 0,5 long, do período de 1961-1990. Estes dados foram utilizados devido à ausência de séries de precipitação e temperatura longas e confiáveis sobre o território brasileiro. A climatologia do CRU foi construída com um número de 19,800 estações para a variável precipitação e 12,092 para a temperatura. Os dados de cada estação foram interpolados para uma grade regular em função da latitude, longitude e elevação utilizando o método "thin-plate splines" (Hutchinson, 1995). Esta técnica de interpolação é robusta em áreas com pontos de dados esparsos ou irregulares.
Dados de circulação atmosférica foram obtidos das Reanálises do "National Center for Environmental Prediction / National Center for Atmospheric Research" (NCEP/NCAR), para o período de 1961-1990 com uma resolução horizontal de 2,5 lat x 2,5 long e 28 níveis na vertical (coordenada sigma) (Kalnay et al., 1996). As variáveis utilizadas neste estudo foram a temperatura, umidade específica $(850 \mathrm{hPa})$, precipitação, pressão no nível médio do mar (PSLM) e vento $(850,500$ e $250 \mathrm{hPa})$.

A área de estudo foi definida entre $25^{\circ} \mathrm{N}-60^{\circ} \mathrm{S}$ e $30^{\circ} \mathrm{W}$ $90^{\circ} \mathrm{W}$, com domínio de toda a América do Sul.

Neste estudo se utilizou a primeira simulação de cada modelo do IPCC AR4 e se realizou o teste de significância seguindo o teste T de "Student" para o nível de significância de 0,05 (95\%), nos viés (anomalia) de precipitação. O teste comprovou que as áreas de anomalias positivas e negativas da precipitação são estatisticamente significativas.

\subsection{Metodologia}

Os mapas das anomalias (viés) de precipitação e temperatura, para o clima presente, foram construídos tendo como média climatológica os dados do CRU do período base de 1961-1990. As anomalias para o clima futuro tiveram como climatologia a média dos dados do modelo correspondente para o período base de 1961-1990. O período do cenário futuro (A2) foi dividido em três climatologias: 2011-2040, 2041-2070 e 2071-2100, para facilitar a análise e observar gradualmente as mudanças no padrão de circulação. Foram calculadas variáveis derivadas, tais como, a convergência de umidade $(850 \mathrm{hPa})$, vorticidade relativa $(250 \mathrm{hPa})$ e linhas de corrente $(850,500$ e 250 hPa) através do pacote GRADs (Doty, 1992). Foram construídos campos médios sazonais: dezembro, janeiro e fevereiro (DJF); março, abril e maio (MAM); junho, julho e agosto (JJA), setembro, outubro e novembro (SON), representando as quatro estações do ano. A identificação dos diferentes sistemas de circulação foi subjetiva, e teve como base o conhecimento de estudos observacionais sobre padrões conceituais dos diferentes sistemas, tais como a Zona de Convergência do Atlântico Sul (ZCAS) (Kodama, 1992; Carvalho et al., 2004), a Zona de Convergência Intertropical (ZCIT) (Uvo, 1989), a Alta da Bolívia e o cavado do Nordeste (AB/CV) (Lenters e Cook, 1997), as Altas Subtropicais do Atlântico e do Pacífico (Rodwell e Hoskins, 2001), os sistemas frontais (SF) (Andrade, 2005), o Jato de Baixos Níveis (JBN) (Marengo et al., 2004) entre outros. Campos das mesmas variáveis dinâmicas utilizando as Reanálises foram construídos, para servir como referência para a variabilidade climatológica, aos campos dos modelos do IPCC AR4, e para verificar a capacidade de representar a circulação atmosférica sobre AS.

Foram calculados os vieses das altas subtropicais do 
Pacífico sul e norte (APS/APN), do Atlântico sul e norte (AAS/ AAN), e da baixa pressão sobre a região da Bolívia e do Paraguai, dos modelos do IPCC AR4 em relação à Reanálise, para o clima presente. Para o futuro os vieses foram calculados em relação à climatologia base (1961-1990) do mesmo modelo. Para isto foram determinadas áreas representativas onde estes sistemas atuam (Figura 1).

Devido as diferentes resoluções que cada modelo apresenta, os dados das variáveis dinâmicas, precipitação e temperatura dos modelos do IPCC AR4 e do CRU foram levadas para a resolução da Reanálise $\left(2,5^{\circ} \times 2,5^{\circ}\right)$. O método de interpolação foi o bilinear, implementado no pacote GrADS.

\section{RESULTADOS}

\section{1. Clima Presente - Variabilidade Sazonal: Século XX}

\section{a) Verão (DJF)}

A estação de verão representa a estação chuvosa nas regiões Sudeste, centro oeste e sul da Amazônia (Rao e Hada, 1990; Marengo, 2007b). Nos modelos analisados do IPCC AR4 (Figura 2a) a maior quantidade de chuva também se concentra sobre estas áreas em diferentes níveis de intensidade. Somente o modelo MIROC estende a área de chuva intensa para o norte

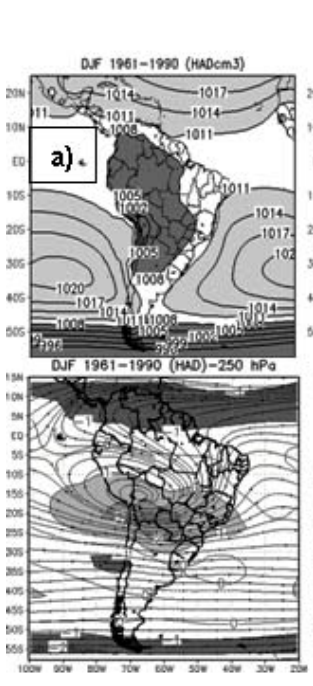

24 $1961-1990$ (1400m3)

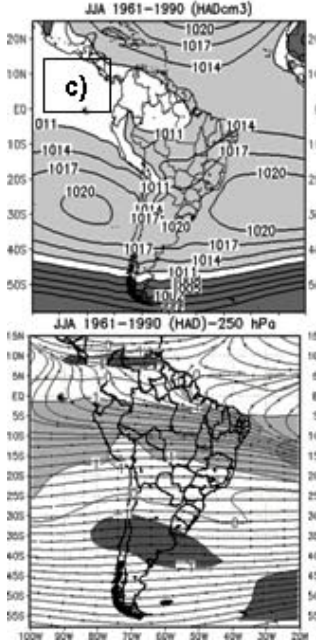

DJF

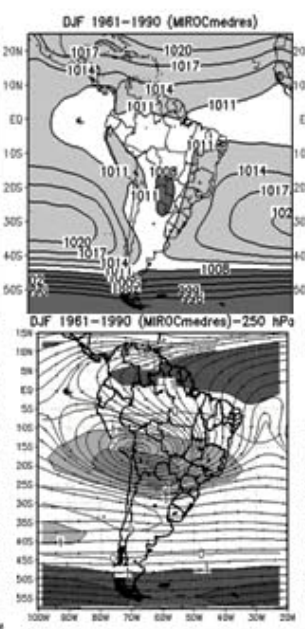

JJA

JuA 1961-1990 (Mirocmetrese)

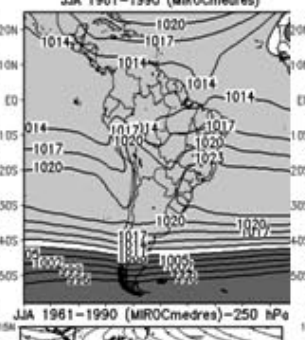

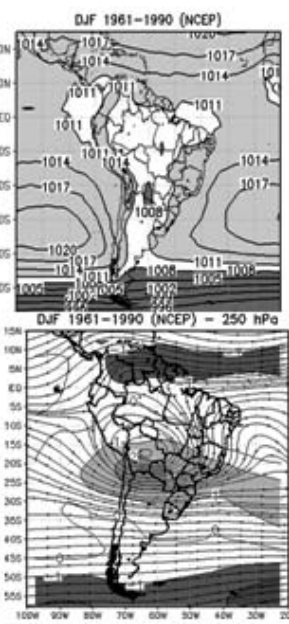

A3A $1961-1990$ (NCEP)

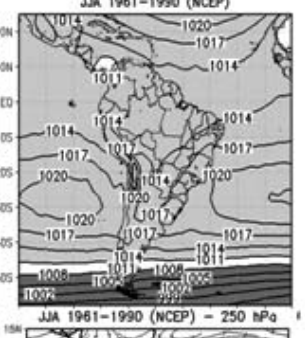

SON 1961-1990 (croc)
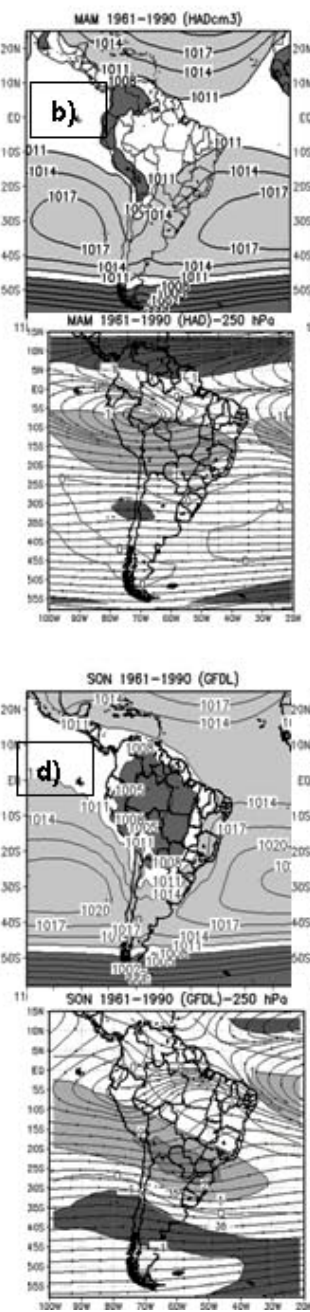

MAM

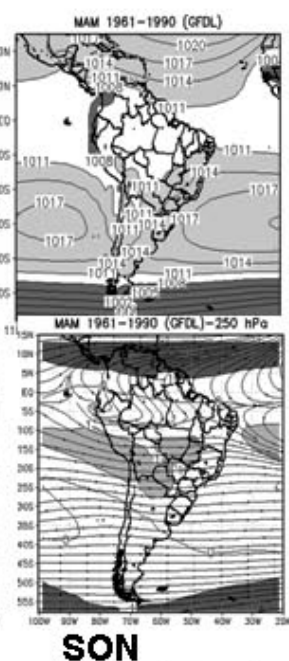

SON 1961-1990 (MIROCmadres)

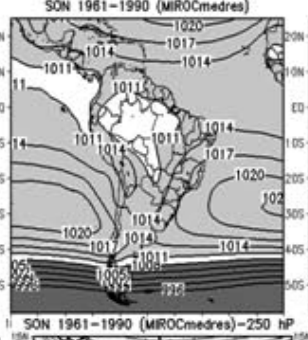

SON $1961-1990$ (NCEP)

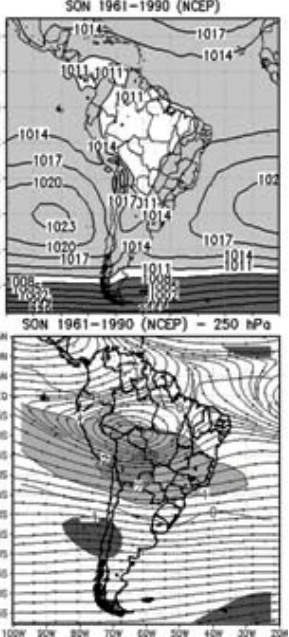

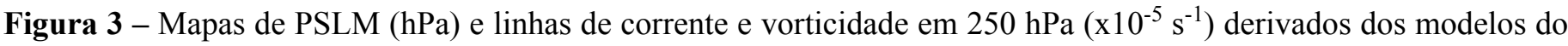
IPCC AR4 e da Reanálise, para as estações de verão (HadCM3 e MIROC), outono (HadCM3 e GFDL), inverno (HadCM3 e MIROC) e primavera (GFDL e MIROC), para o período de 1961-1990. 
(Maranhão e Piauí) e parte do Nordeste. Por outro lado, o HadCM3 simula melhor a banda de chuva orientada de noroeste para sudeste (NW-SE), estendendo-se para o oceano, sugerindo a posição da ZCAS. Porém, pela localização das chuvas máximas, estaria simulando uma ZCAS oceânica (Carvalho et al., 2004), onde a maior precipitação se concentra sobre Goiás, e parte da região Sudeste.

Observa-se nos mapas de precipitação dos modelos HadCM3, GFDL, MIROC e GISS (Figura 2a), sobre os oceanos Atlântico e Pacífico equatorial, uma banda de chuva bem definida associada à ZCIT. O GFDL se destaca com uma banda dupla de precipitação sobre o Atlântico, onde a banda principal se une com a chuva em continente sobre os $5^{\circ} \mathrm{S}$. Sobre o Pacífico a banda dupla é mais fraca. A ZCIT com banda dupla sobre o Atlântico já foi observada e referenciada por Uvo (1989) e Coelho et al. (2004). A simulação da banda dupla da ZCIT tem sido amplamente discutida, especificamente, aquela que se localiza sobre o pacífico tropical leste (Li et al., 2004). Observacionalmente este sistema se forma na primavera e não no verão, como simulado pelo modelo GFDL. Dai (2006) ao analisar a precipitação em 18 modelos do IPCC AR4, apontou que os vieses das chuvas equatoriais associadas à dupla banda da ZCIT estão associados ao resultado equívoco da retroalimentação das nuvens, erro no gradiente equatorial leste-oeste da temperatura superficial do mar, e a outras interações oceanoatmosfera que os modelos de circulação geral não simulam.

Nos mapas de anomalias da chuva (Figura 2b), observase que todos os modelos subestimam a chuva sobre a Amazônia, especificamente o GFDL e o GISS estendem a área de déficit para o Sudeste. Por outro lado, o HadCM3 mostra a área de anomalias negativas apenas sobre parte da Amazônia Brasileira e Guianas. As áreas de anomalias positivas localizam-se sobre o sudeste, centro sul do Brasil, Bolívia e norte do Chile e Argentina $(+4 \mathrm{~mm} / \mathrm{dia})$.

Os cinco modelos superestimam as chuvas sobre os Andes Peruano-Bolivianos, sul do Chile e Argentina e as subestimam (exceto o GISS) sobre Colômbia, Venezuela e Guianas.

Com relação às variáveis dinâmicas analisa-se o campo de pressão ao nível do mar (PSLM), onde o padrão climatológico de verão na região de estudo são as altas subtropicais do Pacífico Sul (APS) e do Atlântico Sul (AAS), e a área de baixa pressão sobre a região do Chaco na Bolívia, no Paraguai, e norte da Argentina. Em relação a esta área de baixa pressão, autores como Lichtenstein (1980) e Seluchi et al. (2003), afirmam que a mesma é conformada por dois núcleos ciclônicos, um localizado sobre o Paraguai e a Bolívia, conhecido como a baixa do Chaco (BCH), e o outro sobre o noroeste da Argentina chamado de baixa do noroeste argentino (BNA). Geralmente estes dois centros podem ser visualizados dentro de uma única área, porém, os autores advertem que as suas características dinâmicas e térmicas são diferentes. Geralmente a $\mathrm{BCH}$ está associada com a divergência da $\mathrm{AB}$ em $250 \mathrm{hPa}$, áreas de máxima precipitação, e é quase estacionário. A BNA é de característica térmo-orográfica e intermitente. Neste trabalho, estes dois núcleos de baixa pressão foram observados como uma única área, que foi chamada de baixa continental (BC). Também foram analisadas as altas subtropicais APN e AAN, para estudar a sua relação com a ZCIT.

Foram calculados os vieses dos sistemas de pressão AAS, APS, AAN, APN e BC dos modelos do IPCC AR4 em relação à Reanálise. Pode-se observar na Tabela 2 que no verão todos os modelos subestimaram a intensidade da APS, sendo o CCCMA $(-2,0 \mathrm{hPa})$ e o GISS $(-2,9 \mathrm{hPa})$ os que apresentaram os vieses mais negativos, sugerindo uma menor subsidência sobre sua área de atuação. Também para a BC todos os modelos apresentaram vieses negativos, o que sugeriu a tendência dos modelos a simular o centro ciclônico mais intenso, e consequentemente, com maior convergência em superfície, especificamente o HadCM3 $(-4,3)$ e o GISS $(-6,9 \mathrm{hPa})$ a simularam muito mais intensa. Em relação à AAS não houve uma característica comum nos vieses, o GISS (GFDL) a subestimou (superestimou) em

Tabela 2 - VIÉS sazonal da pressão ao nível do mar (hPa), em relação à Reanálise, para os modelos do IPCC AR4, dos diferentes sistemas de pressão analisados, e para o período de 1961-1990.

\begin{tabular}{|c|c|c|c|c|c|c|c|c|c|c|c|c|c|c|c|c|c|c|c|c|}
\hline & \multicolumn{5}{|c|}{ DJF } & \multicolumn{5}{|c|}{ MAM } & \multicolumn{5}{|c|}{ JJA } & \multicolumn{5}{|c|}{ SON } \\
\hline & HAD & GFDL & СССMA & MIROC & GISS & HAD & GFDL & СССMA & MIROC & GISS & HAD & GFDL & ССCMA & MIROC & GISS & HAD & GFDL & CCCMA & MIROC & GISS \\
\hline APS & $-0,9$ & $-1,4$ & $-2,0$ & $-0,7$ & $-2,9$ & $-1,2$ & $-1,8$ & $-1,4$ & $-0,5$ & $-2,6$ & -1.0 & $-1,5$ & $-1,8$ & $-0,1$ & $-3,1$ & $-0,9$ & $-0,9$ & $-1,7$ & $-1,4$ & $-3,7$ \\
\hline AAS & $-0,1$ & 0,6 & 0,3 & 0,04 & $-1,1$ & 0,3 & 0,6 & 3,4 & 2,0 & $-1,0$ & 0,2 & 0,5 & 3,9 & 2,3 & $-3,6$ & $-1,1$ & 1,29 & 2,1 & 0,7 & $-3,4$ \\
\hline $\mathrm{BC}$ & -4.3 & $-2,4$ & $-1,4$ & $-1,0$ & $-6,9$ & $-2,2$ & $-1,5$ & 1,2 & 1,7 & $-5,1$ & $-0,4$ & $-0,8$ & 3,9 & 5,3 & $-3,2$ & $-3,5$ & $-2,7$ & 0,9 & 0,9 & $-5,7$ \\
\hline APN & $-2,1$ & $-1,2$ & $-0,8$ & 0,4 & $-2,7$ & $-2,0$ & $-0,7$ & $-0,9$ & 0,09 & $-2,9$ & -2.1 & $-0,7$ & $-1,1$ & 1,2 & $-2,7$ & $-2,8$ & $-1,6$ & $-0,9$ & 0,3 & $-2,9$ \\
\hline AAN & -1.5 & 0,3 & 2,3 & 0,5 & $-2,3$ & $-1,3$ & $-0,5$ & 2,5 & $-0,1$ & $-2,3$ & $-1,3$ & $-1,4$ & 1,8 & $-0,2$ & $-2,7$ & $-1,7$ & $-0,7$ & 2,2 & 0,6 & $-2,6$ \\
\hline
\end{tabular}


$-1,1 \mathrm{hPa}(0,6 \mathrm{hPa})$ mais que os outros modelos. Para a APN e AAN, também se observou diferenças nos modelos, e o GISS foi o que mais subestimou as altas. Dentre os modelos analisados, o MIROC (exceto para a AAN) foi aquele que apresentou os menores vieses, e o GISS o que mais subestimou todos os sistemas.

Analisando a configuração e posição dos sistemas de pressão nos cinco modelos, ressalta-se a localização e extensão da BC. Enquanto a Reanálise (Figura 3a) localiza o centro da BC sobre o sul da Bolívia e norte da Argentina, os modelos analisados do IPCC AR4 (com exceção do MIROC - Figura 3a) simulam o núcleo da $\mathrm{BC}$ posicionado entre o noroeste argentino e o norte do Chile, muito mais intenso do que a Reanálise, explicando os vieses negativos da BC (Tabela 1). No HadCM3 (Figura 3a) foi possível observar o núcleo da $\mathrm{BC}$ estendendo-se para o sul peruano-boliviano, além de estender a área de baixa pressão sobre a Amazônia, centro-oeste e Paraguai. Figueroa et al. (1995) em um estudo de modelagem sugere que a Baixa do Chaco pode também ser uma resposta dinâmica à fonte de calor na Amazônia e Brasil Central, pelo que deve estar ligada à convecção sobre a Amazônia. No entanto, como a convecção sobre a Amazônia é dificilmente bem representada pelos modelos numéricos, provavelmente a $\mathrm{BC}$ também pode ser afetada na sua representação, isto pode explicar a dificuldade dos modelos do IPCC AR4 em localizar a BC sobre sua posição climatológica observacional.

Outro sistema de verão relacionado com o transporte de umidade e calor da Amazônia para latitudes extratropicais altas é o JBN. Neste caso de análise sazonal, observou-se uma circulação de baixos níveis ao leste dos Andes, e o modelo CCCMA (Figura não mostrada) apresentou os ventos mais intensos ao leste dos Andes $(7,39 \mathrm{~m} / \mathrm{s})$ na área em que o JBN se localiza.

A configuração do vento em altos níveis $(250 \mathrm{hPa})$ mostrou na climatologia da Reanálise a coerência da posição da $A B$ em relação a $B C$ em superfície (Figura $3 a$ ). Nos modelos do IPCC AR4 a AB foi simulada com uma configuração alongada zonalmente, com o núcleo deslocado para o oeste em relação à Reanálise. Observa-se na Figura 3a que o modelo HadCM3 apresentou a $\mathrm{AB}$ e o núcleo da $\mathrm{BC}$ deslocados para o noroeste. $\mathrm{A}$ área de máxima vorticidade anticiclônica (divergência) relacionada à intensificação da $\mathrm{AB}$ também se mostrou alongada zonalmente, porém, não se estendeu sobre o setor sudeste e oceano Atlântico como observado na Reanálise.

Outra característica importante da circulação relacionada às chuvas é a configuração da ZCAS. Dinamicamente este sistema se caracteriza pela formação de um cavado na baixa e média troposfera com orientação NW-SE sobre o Sudeste e a Amazônia, uma zona de divergência em altos níveis, e uma zona de convergência de umidade em baixos níveis $(850 \mathrm{hPa})$ sobre estas mesmas áreas. Dentre os modelos analisados do IPCC AR4, o HadCM3 apresentou estas características melhor definidas, embora os núcleos da $\mathrm{AB}$ e da $\mathrm{BC}$ se apresentem deslocados para o noroeste. A Figura 4d mostra o campo de circulação em $500 \mathrm{hPa}$ com o cavado sobre a região Sudeste (nordeste de Minas Gerais) mais deslocado para o norte em relação a climatologia da Reanálise. Também se observa no campo de convergência de umidade em $850 \mathrm{hPa}$, sobreposto ao campo de linhas de corrente (Figura 4d), um núcleo de convergência mais intenso sobre o Sudeste do que sobre a Amazônia. Este modelo também simulou em $850 \mathrm{hPa}$, ventos fortes ao leste dos Andes (Figura 4b). Estes ventos transportam umidade e calor

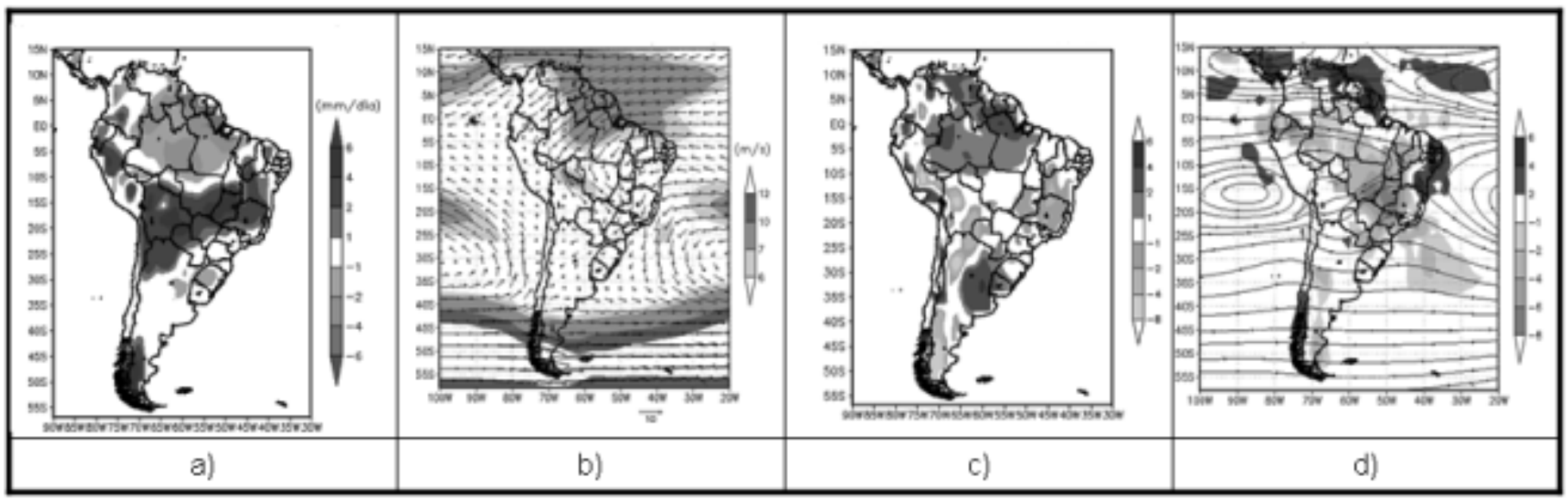

Figura 4 - Mapas anomalia de precipitação (a), campo e velocidade de vento (b), anomalia de temperatura $\left({ }^{\circ} \mathrm{C}\right)(\mathrm{c})$ campo de convergência de umidade $\left(\times 10^{-8} \mathrm{~kg} \mathrm{x} \mathrm{s}^{-1}\right)(\mathrm{d})$, derivados do modelo HadCM3, para a estação de verão, e para o período de 1961-1990. 
para a região Sudeste. Em relação às temperaturas, as anomalias positivas (negativas) (Figura $4 \mathrm{c}$ ) estiveram associadas às regiões mais secas (úmidas) (Figura 4a). No campo de $250 \mathrm{hPa}$, um núcleo intenso de divergência situa-se ao sul do núcleo da $\mathrm{AB}$, coincidindo com a posição da $\mathrm{BC}$ (Figura 3a), e sugerindo convergência em baixos níveis associada a $\mathrm{BC}$.

Nos modelos: CCCMA, GFDL e GISS a ZCAS não foi bem simulada, onde prevaleceu um cavado fraco $(500 \mathrm{hPa}) \mathrm{e}$ pouca convergência de umidade sobre o sudeste, centro oeste e Amazônia o que causou o déficit da chuva sobre estas regiões (Figura 2a).

Todos os modelos apresentam anomalias positivas sobre o norte do Nordeste, sendo o MIROC o que gera anomalias de $+4 \mathrm{~mm}$ /dia sobre o Nordeste (Piauí e Maranhão), por localizar o seu máximo de chuva sobre essas regiões. No GFDL, o excesso de chuva pode estar associado à banda principal da ZCIT localizada sobre $5^{\circ} \mathrm{S}$. Possivelmente, a posição da AAN e AAS mais ao sul (Figura não mostrada), quando comparada com a Reanálise favorece a localização da banda da ZCIT sobre o continente.

É importante ressaltar que os modelos em geral, apresentam dificuldades em simular corretamente a chuva sobre a Amazônia e sobre os Andes. Estudos também têm enfatizado este problema, quando utilizados modelos globais como os do CPTEC/COLA (Cavalcanti et al., 2002; Marengo et al., 2003), do "Geophysic Fluid Dynamic Laboratory" (GFDL) (Stern e Miyakoda 1995) e do "European Centre for medium Range Weather Forecast" (ECMWF) (Brankovic e Molteni 1997), entre outros. A redução de chuva sobre a Amazônia está relacionada com o tipo de esquema de convecção e de camada limite planetária, e o excesso sobre os Andes com a deficiência na representação espectral da topografia, assim como ao erro associado ao efeito Gibbs devido ao truncamento do "steep orography" (Stern e Miyakoda, 1995).

\section{b) Outono (MAM)}

Este período representa a estação chuvosa do norte da Amazônia e do Nordeste (Rao e Hada, 1990; Marengo, 2007b). Nesta época, climatologicamente a banda de convecção associada à ZCIT, se desloca para o sul entre os $5^{\circ} \mathrm{S}-6^{\circ} \mathrm{S}$ (Lobo, 1982) influenciando as chuvas sobre estas regiões. O campo de chuva dos modelos do IPCC AR4 (Figura 2a) apresenta a banda de precipitação sobre o Atlântico associada à ZCIT, onde apenas o GFDL mostra a banda contínua $\left(5^{\circ} \mathrm{S}-6^{\circ} \mathrm{S}\right)$, que atravessa o continente (norte do Nordeste e Amazônia). Isto se associa com as anomalias positivas (Figura $2 b$ ) de chuva sobre o norte do Nordeste, e em uma área menor de déficit sobre o norte da Amazônia em relação aos outros modelos. Por outro lado, o MIROC, GISS e CCCMA apresentam uma área maior de anomalias negativas de chuva sobre toda a Amazônia
(Figura 2b). O CCCMA mostra anomalias de $-6 \mathrm{~mm} /$ dia sobre a Amazônia Peruana, as Guianas e norte do Pará. Estes três modelos, também apresentam anomalias positivas sobre o Nordeste, pois a banda de precipitação associada à ZCIT, apesar de estar localizada mais ao norte em relação ao GFDL, estende seu campo de umidade sobre esse setor. Em geral, os modelos subestimam a chuva sobre o sul e sudeste do Brasil e Paraguai, e a superestimam sobre o norte e sul do Chile e noroeste Argentino (Figura 2b).

Em relação aos campos de pressão e a posição da ZCIT, climatologicamente sabe-se que ao ocorrer um deslocamento da ZCIT para o sul $\left(5^{\circ} \mathrm{S}\right)$, a AAS (AAN) se enfraquece (intensificase) e se desloca para o sul. A intensificação e o deslocamento para o sul da AAN, possibilitam que os ventos alísios do nordeste ingressem ao Hemisfério Sul levando umidade e calor, contribuindo para a formação da banda convectiva da ZCIT (Hastenrath e Heller, 1977).

Os vieses das altas subtropicais em relação à Reanálise são mostrados na Tabela 2. A APS é simulada menos intensa pelos modelos do IPCC AR4, sendo o GISS que apresenta o viés mais negativo de $-2,6 \mathrm{hPa}$. Por outro lado, a AAS apresenta um viés positivo (exceto pelo GISS), onde o CCCMA a simula mais intensa com um viés de $3,4 \mathrm{hPa}$. A APN (AAN) também é simulada menos intensa a exceção do modelo MIROC (CCCMA). O modelo GISS subestimou mais os centros de alta pressão, igualmente ocorrido na época de verão.

$\mathrm{Na}$ Figura 3b são apresentadas as configurações do campo de PSLM, para os modelos HadCM3, GFDL e Reanálise. Quando se compara o mapa da Reanálise desta estação com a do verão (Figura 3a), observa-se o ligeiro deslocamento da AAN e da AAS para o sul. Nos modelos do IPCC AR4, esta característica também foi bem representada pelo modelo GFDL (Figura $3 b$ ), que mostrou a ZCIT sobre $6^{\circ} \mathrm{S}$, com o deslocamento da AAN para o sul (inclusive mais ao sul que a Reanálise). Este comportamento coincidiu com uma menor área de anomalias negativas de precipitação na região norte da Amazônia, e com a área de anomalias positivas sobre o norte do nordeste do Brasil (Fig 2 a,b).

A AAN no modelo HadCM3 (Figura 3b) também se desloca ligeiramente para o sul (não tanto como no GFDL e MIROC - Figuras não apresentadas), e a AAS se enfraquece em relação á época de verão. Isto contribui para que a ZCIT se localize acima de $5^{\circ} \mathrm{S}$, porém com uma faixa de precipitação descontínua. Sobre o Pacífico a ZCIT é intensa e se estende de $5^{\circ} \mathrm{N}-5^{\circ} \mathrm{S}$ sobre o Equador, Peru e Colômbia (Figura 2a), o que coincide com a maior convergência de umidade em $850 \mathrm{hPa}$ (Figura não mostrada) sobre o oeste da Amazônia, onde não foram observadas anomalias negativas de chuva (Figura $2 b$ ). O CCCMA apresenta as AAN e AAS intensas (vieses positivos - Tabela 2) e fusionadas, enfraquecendo a zona de convergência 
em baixos níveis, sobre o cavado equatorial, o que origina uma ZCIT extremamente fraca no oceano (Figura 2a). No MIROC, o deslocamento da AAN para o sul também é observado, porém o deslocamento e enfraquecimento da AAS para o sul não acontece, o que influencia na redução de chuva sobre o norte da Amazônia. O GISS não apresenta a AAN deslocada para o sul. No entanto, o cavado equatorial intenso se associa com a chuva sobre a linha do equador, estendendo-se para o norte do Nordeste (Figura 2).

No campo de $250 \mathrm{hPa}$ (Figura $3 \mathrm{~b}$ ), a AB se desloca para o norte, devido a diminuição da convecção, como observado no campo da Reanálise. Nos modelos do IPCC AR4 (HadCM3, GFDL e MIROC) este sistema também se desloca mais para o noroeste do continente. Ressalta-se a configuração do HadCM3 (Figura 3b), que ainda apresenta a circulação anticiclônica bem definida sobre noroeste da Amazônia, o que coincide com a área de baixa pressão em superfície sobre a Colômbia e Equador (que os outros modelos não apresentam). Esta configuração pode estar associada às chuvas significativas sobre essa região (Figura 2a), com convergência em baixos níveis e divergência em altos níveis.

\section{c) Inverno (JJA)}

Esta estação se caracteriza por chuvas escassas sobre o Brasil, sobretudo, no sudeste e centro leste, devido à diminuição do gradiente de temperatura e conseqüentemente a falta de convecção. Geralmente as chuvas deslocam-se para o norte do continente, seguindo a localização climatológica da ZCIT ao redor de $10^{\circ} \mathrm{N}$ (Lobo, 1982). No entanto, sobre o norte da Amazônia ainda as chuvas são consideráveis. A ZCIT identificada nos mapas de precipitação, nos diferentes modelos localiza-se acima de $5^{\circ} \mathrm{N}$ (Figura 2a), consequentemente as chuvas sobre o Norte da Amazônia e sobre o Nordeste diminuíram consideravelmente. Sobre o Pacifico a banda da ZCIT acima de $5^{\circ} \mathrm{N}$ esteve mais intensa nos modelos CCCMA e HadCM3. Nesta época, a ZCIT do Pacífico se localiza entre $6^{\circ}-8^{\circ} \mathrm{N}$, pois a TSM é mais elevada que no Hemisfério Sul (Takahashi e Battisti, 2007), e o deslocamento da APS para o norte inibe a convecção profunda por subsidência.

Em relação às anomalias de chuva a Figura $2 b$ mostra que todos os modelos subestimam a precipitação sobre o norte do continente (incluindo a região da Amazônia) e sobre o Uruguai e sul do Brasil. Os modelos GFDL, MIROC e GISS mostram anomalias negativas mais intensas $(-4 \mathrm{~mm} / \mathrm{dia})$ sobre o sul do Brasil. Pode-se inferir que o CCCMA simula melhor as chuvas sobre o sul do Brasil (Figura 2a), produzidas por sistemas transientes e pelos SFs que são mais freqüentes no inverno, pois subestima em menor intensidade as chuvas sobre esta região. Outra característica comum dos modelos é a área de anomalias positivas de chuva sobre o sul do Chile e a Argentina.

A Tabela 2 mostra o viés em relação à Reanálise e observa-se que a APS é subestimada em intensidade pelos cinco modelos do IPCC AR4, sugerindo menor subsidência, sendo o GISS (MIROC) o que mais (menos) a subestima. Por outro lado, o modelo CCCMA (GISS) superestima (subestima) mais a AAS em relação aos outros modelos.

Quanto à posição dos sistemas de pressão, todos os modelos do IPCC AR4 deslocam o núcleo das altas subtropicais para o norte, quando comparado às outras estações, além da AAS ser mais intensa. Devido à falta de aquecimento (temperaturas baixas) e ausência de convecção no continente, o deslocamento das altas tem como função misturar as massas de ar mais frias (latitudes médias) com as menos frias (latitudes tropicais), originando o contraste de temperatura e favorecendo a formação das nuvens características das frentes.

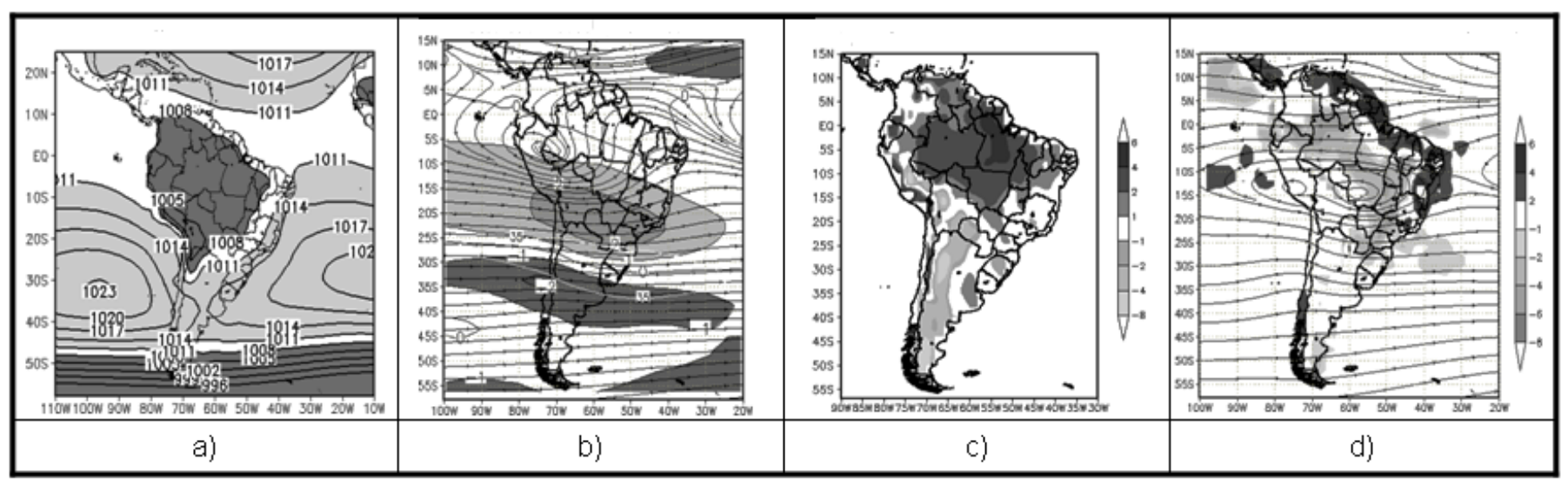

Figura 5 - Mapas de PSLM (hPa) (a), campo de linhas de corrente e vorticidade ( $\left.\times 10^{-5} \mathrm{~s}^{-1}\right)(\mathrm{b})$, anomalia de temperatura $\left({ }^{\circ} \mathrm{C}\right)$ (c) e campo de convergência de umidade $\left(\mathrm{x}^{-8} 0^{-8} \mathrm{~kg} \mathrm{x} \mathrm{s}^{-1}\right)$, derivados do modelo HadCM3, para a estação de primavera e para o período de 1961-1990. 

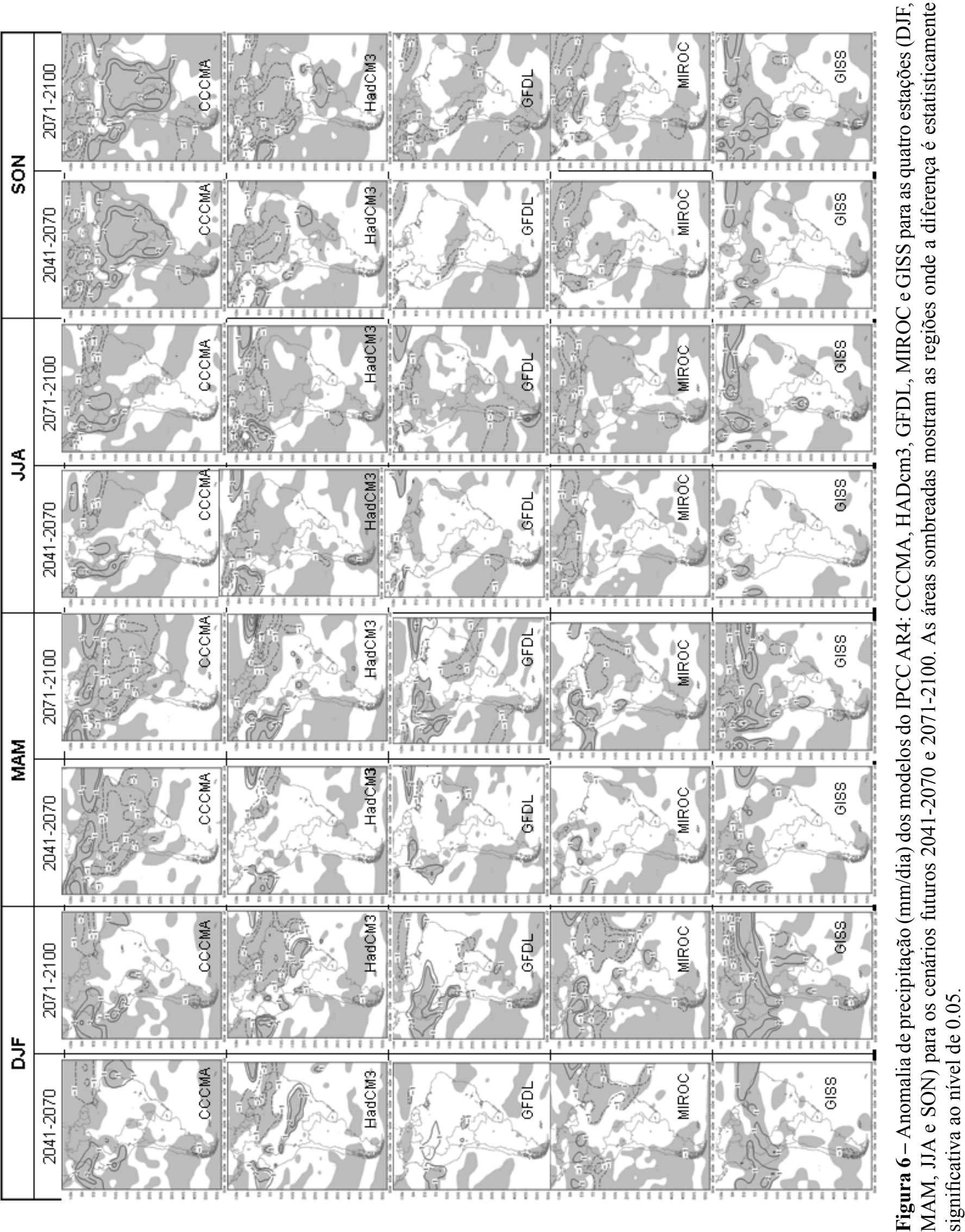
Na configuração da PSLM para esta estação podem ser identificados dois padrões similares ao observado no estudo de Andrade (2005) sobre climatologia de SFs, em relação à localização das frentes e sua produção de chuvas sobre o sul e sudeste do Brasil. O primeiro padrão com uma AAS (MIROC e GFDL) (Figura 3c) intensa deslocada sobre a costa leste, o que dificulta as passagens dos SFs sobre a região sul e sudeste do Brasil, e o que pode explicar as fortes anomalias negativas de chuva sobre a região sul (Figura 2b). O outro padrão evidenciado pelo HadCM3 (Figura 3c) mostrou uma APS menos intensa próxima ao continente, e uma AAS mais fraca em relação ao MIROC e GFDL, e afastada da costa. Esta situação pode ter favorecido as passagens dos SFs sobre o sul e sudeste, pois existe menos subsidência, o que também pode ser corroborado no campo de vorticidade (Figura $3 \mathrm{c}$ ), pois apresenta uma faixa de vorticidade ciclônica entre os $32^{\circ} \mathrm{S}-42^{\circ} \mathrm{S}$, que pode indicar atividade frontal ou de ciclogênese. No mapa de precipitação o HadCM3 mostrou chuva nessa região com um déficit menor (Figura 2b) em relação ao MIROC e GFDL.

\section{d) Primavera (SON)}

Nesta estação se configura o padrão de circulação associado com as chuvas sobre a região tropical. Nos modelos do IPCC AR4 ainda continuam-se observando anomalias negativas de chuva sobre o centro do continente, porém o GFDL (Figura $2 b)$ apresenta anomalias negativas de chuva mais intensas (-4 $\mathrm{mm} / \mathrm{dia}$ ) sobre a Amazônia, e que se estendem praticamente sobre todo o território brasileiro. Por outro lado, o HadCM3 é o que menos subestima as chuvas (Figura 2b), com anomalias negativas sobre o oeste do nordeste, e positivas sobre a Bolívia, norte da Argentina e centro oeste do Brasil.

No campo de PSLM, os vieses da APS continuam negativos em todos os modelos (Tabela 2). Por outro lado, a AAS é simulada pelo GISS mais fraca, e a BC ligeiramente mais fraca que os modelos CCCMA e MIROC, e muito mais intensa no HadCM3, GFDL e GISS, sugerindo maior convergência em baixos níveis na simulação destes modelos.
Por outro lado, a Reanálise (Figura 3d) mostra o início de uma configuração típica de chuva, com as altas subtropicais mais afastadas do continente e a $\mathrm{AB}$ configurada sobre centro do continente com seu núcleo divergente intenso.

Somente o MIROC (Figura 3d) e o CCCMA, apresentaram ainda um padrão de inverno com a $\mathrm{BC}$ não definida (vieses positivos - Tabela 2). O GFDL (Figura 3d), que reduz mais a chuva sobre o território brasileiro (Figura 2b) apresentou uma área de baixa pressão sobre o centro do continente (1005 $\mathrm{hPa}$ ), que esteve associada ao forte aquecimento em superfície (Figura não mostrada), com anomalias positivas de temperatura e pouca umidade simulada pelo modelo. A isto se acrescenta a configuração da $\mathrm{AB}$ ou crista deslocada para o noroeste do continente (sobre o Peru e Equador) (Figura 3d).

Por outro lado, o HadCM3 que apresentou menor redução de chuva sobre o território brasileiro (Figura 2a), além de simular o centro da BC (sobre o sul da Bolívia e do Peru - $1005 \mathrm{hPa}$ ) (Figura 5a), configurou melhor a $\mathrm{AB}$ e o cavado do Nordeste (embora deslocado sobre o oeste brasileiro) em comparação aos outros modelos. Associada à $\mathrm{AB}$ observou-se uma forte divergência dos ventos (Figura $5 \mathrm{~b}$ ), convergência de umidade em $850 \mathrm{hPa}$ (Figura 5d) sobre a região das ZCAS, e anomalias positivas de temperatura (Figura 5c) no Brasil central. Também, observou-se uma faixa de vorticidade ciclônica sobre os $30^{\circ}-35^{\circ} \mathrm{S}$, junto com o jato subtropical, o que sugeriu instabilidade associada a chuva. Nos outros modelos (CCCMA e MIROC) a crista/cavado em $250 \mathrm{hPa}$ esteve deslocado para o noroeste do continente.

\section{2 - Cenários Futuros: Século XXI}

As análises das climatologias futuras indicam que as mudanças mais significativas ocorreram a partir da climatologia 2040-2071, estando mais acentuadas no período de 2071-2100. Todavia, ressalta-se que não foram incluídos os campos de precipitação durante o período de 2011-2040; e os campos de circulação representam somente o período de 2071-2100.

Tabela 3 - VIÉS sazonal da pressão ao nível do mar (hPa) dos diferentes sistemas de pressão analisados, para os modelos do IPCC AR4, do período de 2071-2100 em relação ao período de 1961-1990.

\begin{tabular}{|c|c|c|c|c|c|c|c|c|c|c|c|c|c|c|c|c|c|c|c|c|}
\hline & \multicolumn{5}{|c|}{ DJF } & \multicolumn{5}{|c|}{ MAM } & \multicolumn{5}{|c|}{ JJA } & \multicolumn{5}{|c|}{ SON } \\
\hline & HAD & GFDL & CCCMA & MIROC & GISS & HAD & GFDL & CCCMA & MIROC & GISS & HAD & GFDL & CCCMA & MIROC & GISS & HAD & GFDL & CCCMA & MIROC & GISS \\
\hline APS & $-0,9$ & 1.0 & 0,9 & 1,2 & $-0,1$ & -0.2 & 1,8 & 1,6 & 1,2 & 0,9 & 0.5 & 3.1 & 0,7 & 1,9 & 1,2 & $-0,1$ & 2.3 & 0,7 & 2,2 & 0,6 \\
\hline AAS & $-0,4$ & 0,9 & 1,5 & 0,5 & 0,0 & -0.5 & 1.1 & 2,2 & 0,7 & 0,2 & -0.6 & 1.9 & $-0,2$ & 1,3 & 0,5 & -0.2 & 1,5 & $-1,4$ & 1,2 & 0,9 \\
\hline $\mathrm{BC}$ & -1.6 & 0.2 & 0,7 & 0,1 & $-0,4$ & -1.7 & -0.3 & 2,6 & 0,5 & $-0,2$ & -2.1 & 0,2 & $-2,7$ & 0,2 & 0,0 & -2.2 & -0.4 & $-2,7$ & 0,2 & $-0,2$ \\
\hline APN & -1.4 & 0,4 & $-0,6$ & 0,5 & 0.1 & -1.2 & 0,4 & 0,1 & 0,5 & 0.1 & $-1,0$ & 0,6 & $-0,1$ & 0,3 & 0.4 & -1.1 & 0,3 & 0,2 & 0,5 & 0.2 \\
\hline AAN & -0.9 & 0,2 & $-0,3$ & $-1,0$ & $-0,2$ & -0.9 & 0.0 & 0,0 & $-0,1$ & 0,1 & -0.7 & 0.7 & $-1,1$ & 0,0 & 0,0 & -0.2 & 0.3 & 0,3 & $-0,2$ & $-0,1$ \\
\hline
\end{tabular}




\section{a) Verão (DJF)}

A característica em comum observada pelos modelos foi o incremento da precipitação, em relação a sua climatologia (1961-1990), sobre o Pacífico leste equatorial, o que originou a anomalia positiva de chuva sobre esta área, próximo a costa noroeste da América do Sul (Equador, norte do Peru e sul da Colômbia) entre os $5^{\circ} \mathrm{Ne} 10^{\circ} \mathrm{S}$ (ZCIT), e que em alguns modelos (GFDL, MIROC e GISS) se estendeu até o Amazonas (Figura 6).

Dependendo do modelo e da localização da faixa da anomalia positiva de chuva, a posição da APS apresentou um comportamento diferente. Quando a área de anomalia positiva se localizava entre $0^{\circ}-7^{\circ} \mathrm{S}$ (HadCM3 e GISS) (Figura 7b, 7e), a APS teve uma ligeira desintensificação (vieses Tabela 3), com menor subsidência, e um deslocamento para o sul. No GFDL e GISS não foi evidente o deslocamento para o sul da APS, porém o GISS apresentou uma ligeira desintensificação do APS (Tabela 3), e uma AAS mais próxima ao continente.

Por outro lado, quando a ZCIT se localizou ao redor dos $5^{\circ} \mathrm{N}$ (MIROC e CCCMA), a APS se deslocou para o norte (Figura 7d, 7a) e mostrou ligeira intensificação (Tabela
3 - vieses). Outra característica observada nos modelos HadCM3 e MIROC foi a área de anomalia negativa de chuva sobre o Nordeste (-3 $\mathrm{mm} / \mathrm{dia})$, que se estendeu para o leste da Amazônia (-4 mm/dia) no HadCM3, e para o norte do Sudeste no MIROC (Figura 6), e que não foi observada na climatologia presente. A circulação associada com esse comportamento mostrou o deslocamento para o norte da AAN (ligeiramente enfraquecida - Tabela 3) e da banda chuvosa associada à ZCIT. O deslocamento da AAS para o norte no HadCM3 (Figura 7b), contribuiu com subsidência para a inibição das chuvas.

Em relação aos modelos que simularam anomalias positivas de chuva sobre a Amazônia (GISS e GFDL) (Figura 6), observou-se que a AAS se aproximou mais ao continente em relação à climatologia (1961-1990). Em altos níveis (200 $\mathrm{hPa})$ a $\mathrm{AB}$ se deslocou para o norte em relação ao observado no período de 1961-1990. Especificamente no modelo GISS que apresentou dois núcleos fragmentados associados à $\mathrm{AB}$, observou-se que se intensificaram e se deslocaram para o norte, situando-se um deles sobre Rondônia e Mato Grosso (Figura 7e). O campo de convergência de umidade mostrou maior

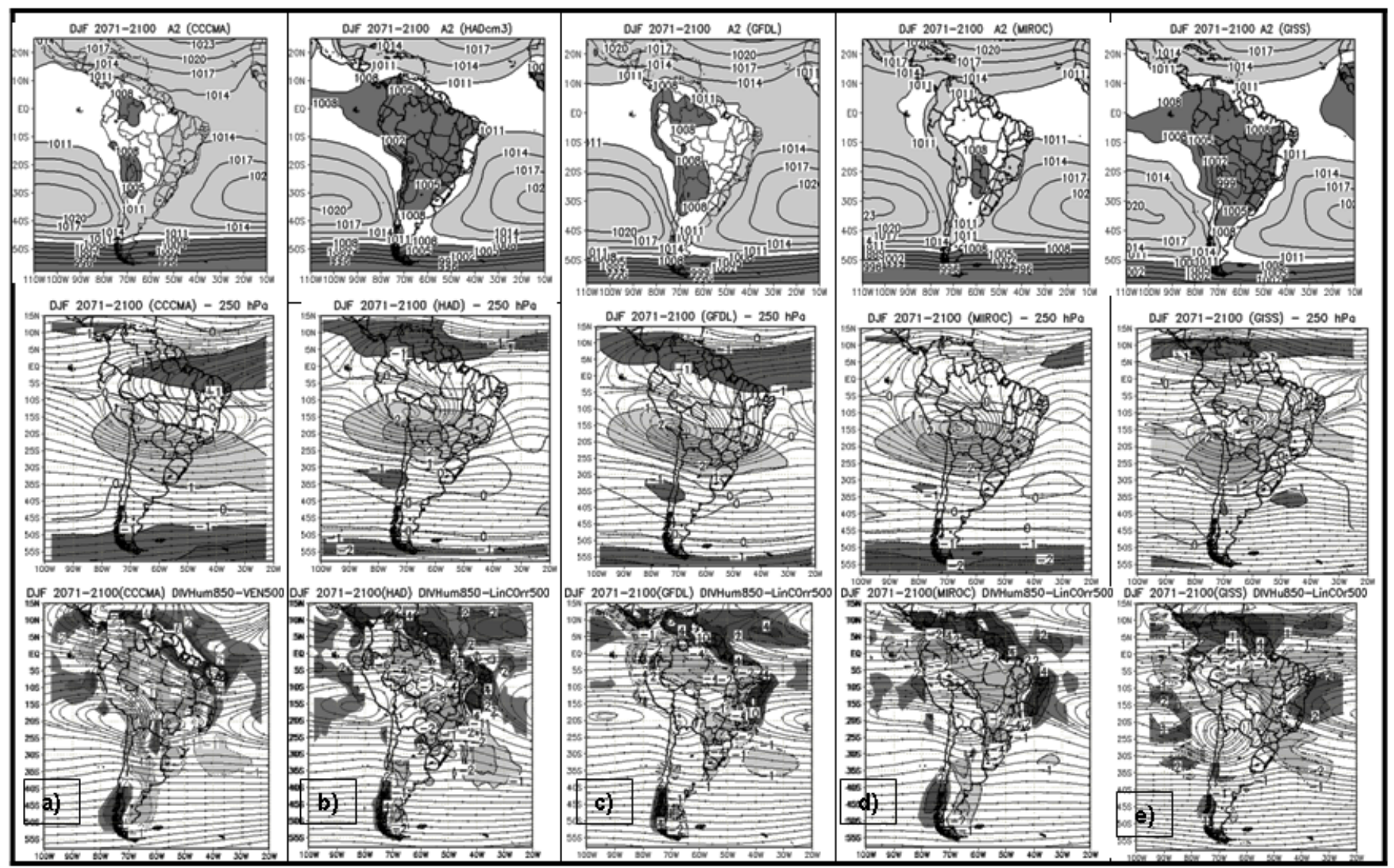

Figura 7 - Mapas de PSLM, linhas de corrente e vorticidade $(250 \mathrm{hPa})$, divergência de umidade (850hPa) e líneas de corrente em $500 \mathrm{hPa}$, e anomalia de temperatura, derivado do modelo CCCMA, HadCM3, GFDL, MIROC e GISS, para o cenário futuro: 2071-2100 e para a estação de verão. 
concentração de umidade sobre o norte do Nordeste, leste da Amazônia e Sudeste, e se associou com as chuvas sobre essas regiões (Figura 6). O GFDL também mostrou o deslocamento da AB para o norte, com seu centro sobre a fronteira do sul do Peru com a Bolívia (Figura 7c).

A circulação da ZCAS (cavado em 500 hPa e convergência de umidade em $850 \mathrm{hPa}$ ), nos modelos CCCMA e GFDL continuou pouco configurada, e não mudou o padrão de anomalias negativas de chuva sobre o norte do Sudeste e centro oeste (Figura 6) que já era observado no clima presente (Figura 2b). Por outro lado, o HadCM3 mostrou alteração na configuração da ZCAS, a extensão da $\mathrm{AB}$ diminuiu e o núcleo deslocou-se para o oeste (Figura $7 \mathrm{~b}$ ). Isto influenciou no cavado em $500 \mathrm{hPa}$ que se estendeu também para o oeste, deslocando ligeiramente para o sul seu padrão de chuva (ZCAS). Este comportamento reforçou as anomalias positivas de precipitação (+4 mm/dia) sobre o norte do Sudeste. No modelo GISS observou-se também o cavado bem configurado em $500 \mathrm{hPa}$, localizado sobre o Sudeste e a banda de convergência de umidade sobre a mesma região estendendo-se sobre o Atlântico (Figura 7e).

A BC simulada pelos modelos para cenários futuros também continuou deslocada para o oeste da sua posição climatológica (a exceção do MIROC). Especificamente, os modelos HadCM3 e GISS se caraterizaram por apresentar uma BC mais intensa (Tabela 3 - vieses) e extensa, associada com a isóbara de $1008 \mathrm{hPa}$, que se estende sobre grande parte do continente e sobre o Pacífico equatorial, reforçando a convergência dos ventos sobre a ZCIT.

A ZCIT e a APS deslocadas para o sul associadas com déficit de chuva sobre o Nordeste são características de El Niño. Estas mesmas características foram observadas na climatologia 2071-2100 do modelo HadCM3.

\section{b) Outono (MAM)}

Para esta estação as mudanças mais significativas aconteceram na climatologia futura 2071-2100 (a exceção do CCCMA). Continuou-se observando em todos os modelos a

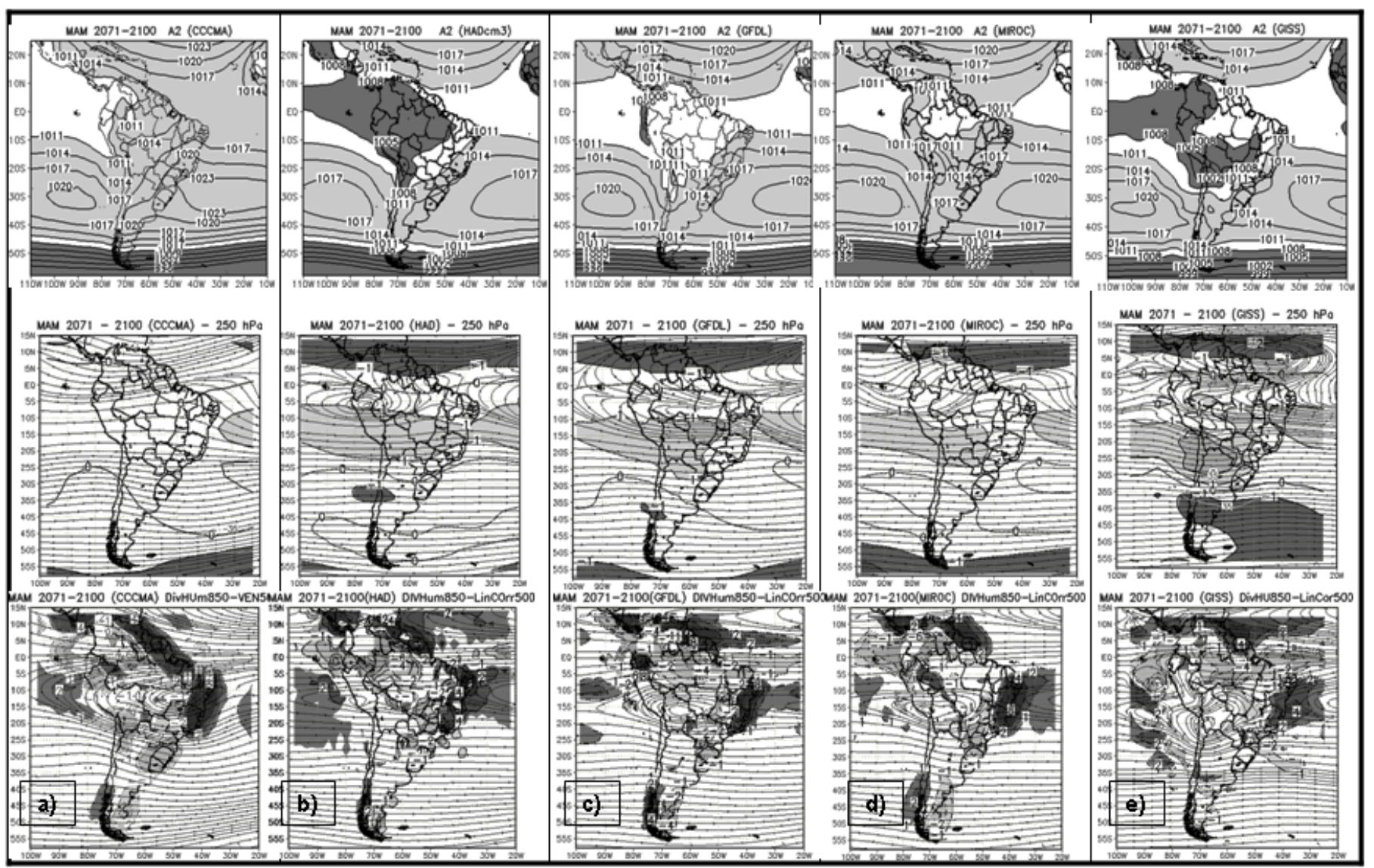

Figura 8 - Mapas de PSLM, linhas de corrente e vorticidade (250 hPa), convergência de umidade (850hPa) e líneas de corrente em $500 \mathrm{hPa}$, e anomalia de temperatura, derivado do modelo CCCMA, HadCM3, GFDL, MIROC e GISS, para o cenário futuro: 2071-2100 e para a estação do outono. 
banda de chuva sobre o Pacifico Equatorial leste, costa norte do Peru, Equador e Colômbia, oscilando entre os $11^{\circ} \mathrm{N}-10^{\circ} \mathrm{S}$, associado à ZCIT. O modelo CCCMA mostrou as ZCITs do Pacífico e do Atlântico intensas, com anomalias positivas sobre o oceano e continente (na linha equatorial), e por debaixo dos $5^{\circ} \mathrm{S}$ observou-se uma área extensa de anomalias negativas de chuva (Figura 6) cobrindo quase todo o território brasileiro, Cordilheira peruana e parte da Bolívia. No campo de circulação deste modelo (Figura 8a) observou-se uma diminuição na concentração de umidade sobre a região da Amazônia e sobre o Peru, em relação à climatologia (1961-1990). Também, observou-se em $500 \mathrm{hPa}$ o enfraquecimento do núcleo da alta $\mathrm{AB}$, com um mínimo de divergência (vorticidade anticiclônica), e uma configuração mais zonal dos ventos em $200 \mathrm{hPa}$. Outra característica deste modelo é a AAS intensa (Tabela 3 - vieses) e deslocada para o noroeste, junto com a AAN ligeiramente deslocada para o norte, o que impediu que a ZCIT se posicionasse ao sul. Sobre o Pacífico a banda da ZCIT se intensifica acima de $5^{\circ} \mathrm{N}$, e estende-se para o norte da Amazônia (Figura 6) com uma intensificação simultânea da APS (Tabela 3 - vieses).
O HadCM3 apresentou anomalias negativas sobre o Nordeste e leste da Amazônia com anomalias negativas intensas de $-3 \mathrm{~mm} /$ dia sobre o norte do Nordeste e norte da Amazônia. O MIROC também apresentou anomalias negativas sobre o norte do Nordeste, porém não tão intensas como no modelo anterior.

No campo de pressão, o HadCM3 apresentou o deslocamento da AAN para o norte (Figura $8 b$ ), e o aumento na intensidade da ZCIT no Pacífico $\left(3^{\circ}-7^{\circ} \mathrm{S}\right)$ coincide com a posição da $\mathrm{AB}$ deslocada para o noroeste do continente, $\mathrm{e}$ a área de baixa pressão em superfície que estende-se para o Pacífico equatorial (Figura 8b). Além disso, a APS torna-se fraca (Tabela 3 - vieses) e desloca-se para o sul, o que denota características similares ao El Niño, que já se vinham observando desde a época do verão.

O MIROC (Figura 8d) mostrou o deslocamento da AAN para o sudoeste, porém a AAS mais intensa (Tabela 3) deslocou-se ligeiramente para o norte, o que fez com que a ZCIT se estreite, afastando-a do norte do Nordeste.

O GFDL e o MIROC mostraram anomalias positivas de chuva ( $+3 \mathrm{~mm} / \mathrm{dia})$ sobre o noroeste da Amazônia, sul da Colômbia, norte do Peru e a Bolívia (Figura 6). O modelo GISS

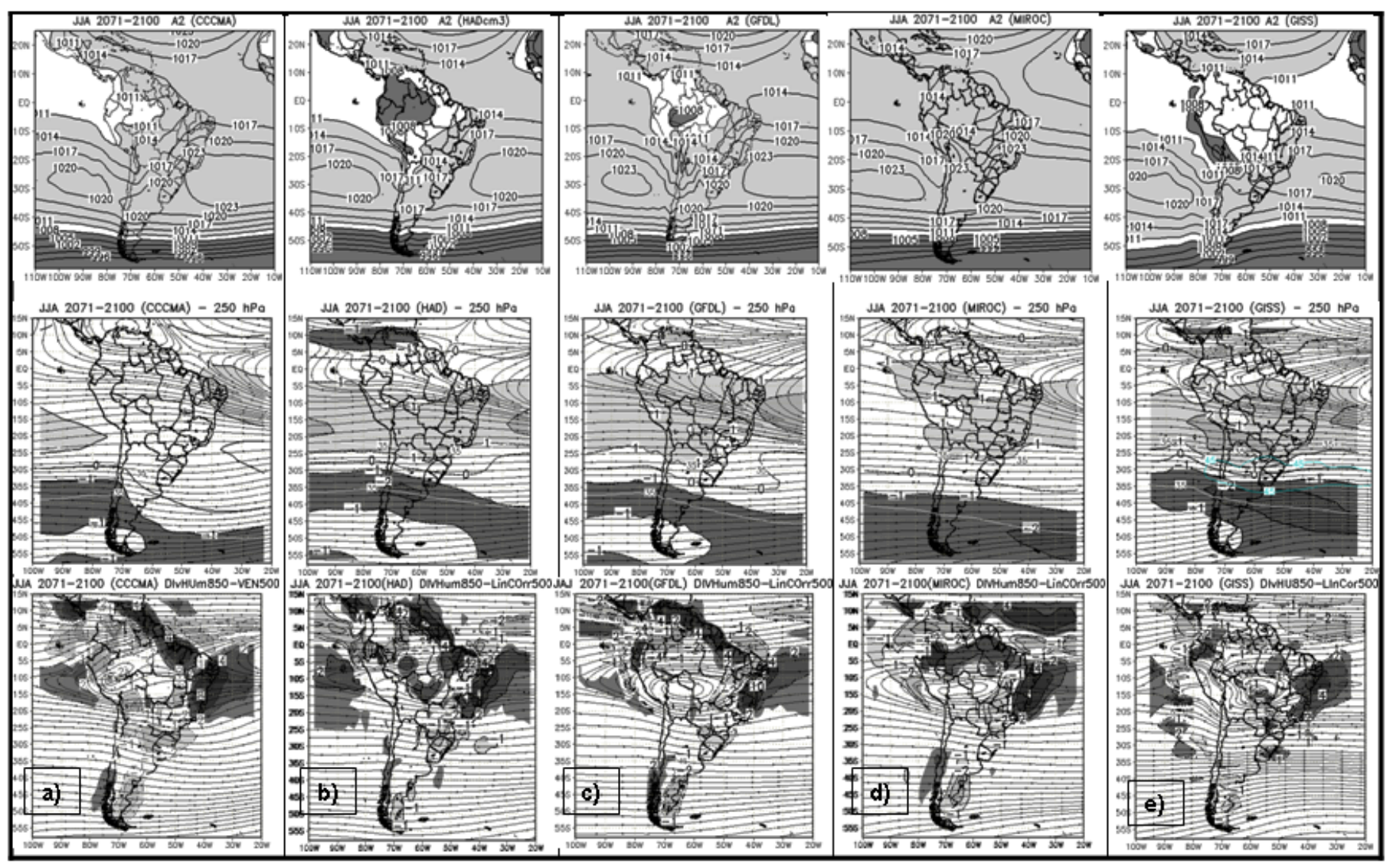

Figura 9 - Mapas de PSLM, linhas de corrente e vorticidade (250 hPa), convergência de umidade (850hPa) e líneas de corrente em $500 \mathrm{hPa}$, e anomalia de temperatura, derivado do modelo CCCMA, HadCM3, GFDL, MIROC e GISS, para o cenário futuro: 2071-2100 e para a estação de inverno. 
também mostrou anomalias positivas, porém estendendo-se para o sul, sobre o centro do Peru, oeste e sul do Amazonas.

A configuração atmosférica no GFDL (Figura 8c) mostrou a APS intensa (Tabela 3 ) e deslocada para o sul. AAPN também se deslocou para o sul, o que contribuiu na localização da ZCIT do Pacífico entre os $0^{\circ}-7^{\circ} \mathrm{S}$, ocasionando as anomalias positivas sobre a costa peruana e equatoriana. No GISS (Figura 8e), também se observou o mesmo comportamento para o APS, além do deslocamento para o sul da AAN e da AAS, contribuindo com o posicionamento e intensificação da ZCIT sobre o Atlântico.

O campo de convergência de umidade (Figura 8e) confirma a maior umidade na região da ZCIT do Atlântico (GFDL e GISS) e do Pacífico (GISS e MIROC).

\section{c) Inverno (JJA)}

Nesta estação não se observaram características comuns nos modelos, além de mostrar poucas mudanças no campo de precipitação (Figura 6).

O CCCMA reforçou as anomalias negativas sobre as Guianas, norte do Pará, e Atlântico (-4 mm/dia) (Figura 6), devido ao ligeiro enfraquecimento (Tabela 3 - vieses) e deslocamento para o norte da AAN (Figura 9a), e conseqüentemente da ZCIT. $\mathrm{O}$ HadCM3 reforçou as anomalias negativas sobre o norte do continente até o norte da Amazônia $(-3 \mathrm{~mm} / \mathrm{dia})$, e mostrou a ZCIT do Pacífico intensa, próxima às costas do Equador, norte do Peru e sudoeste da Colômbia (2071-2100) (Figura 6). Associado com este comportamento, observou-se no HadCM3 o núcleo da APS ligeiramente intenso (Tabela 3) e deslocado para sudeste próximo à costa chilena, assim como uma extensa área ciclônica sobre o noroeste do continente (Amazônia) (Figura 9b).

O GFDL mostrou uma área de déficit de chuva sobre Chile central, que pode estar associada com a intensificação do núcleo da APS (Figura 9c) (Tabela 3), que se deslocou mais para continente sobre a costa central do Chile. Pode-se inferir que a subsidência acentuada sobre essa região impede o deslocamento de sistemas sinóticos de chuva, o que consequentemente origina o déficit.

Por outro lado, o MIROC (Figura 6) não mostrou mudanças significativas no padrão de chuva sobre o continente. No entanto, mostra a APS (Figura 9d) intensa (Tabela 3 - vieses),

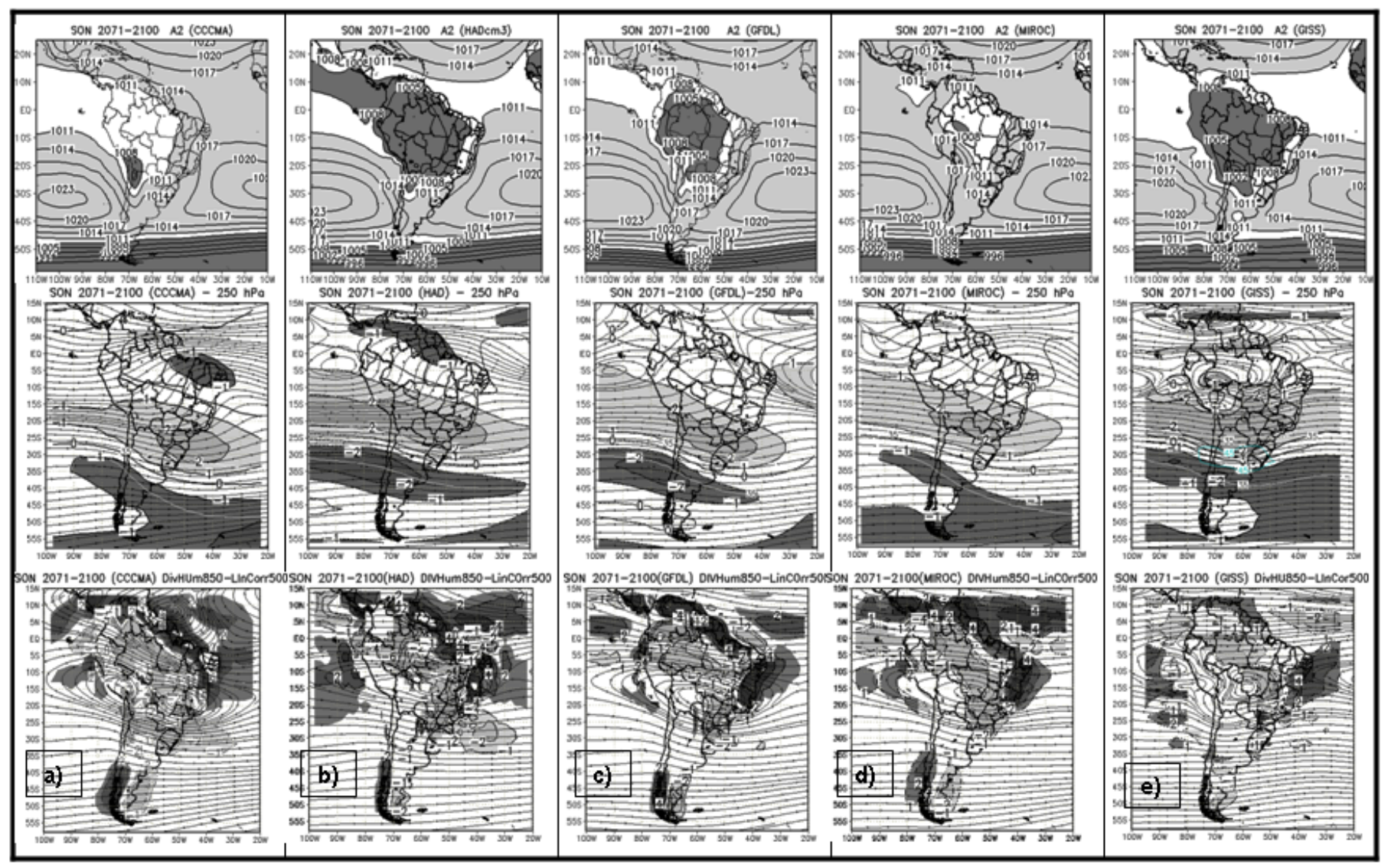

Figura 10 - Mapas de PSLM, linhas de corrente e vorticidade $(250 \mathrm{hPa})$, convergência de umidade $(850 \mathrm{hPa})$ e líneas de corrente em $500 \mathrm{hPa}$, e anomalia de temperatura, derivado do modelo CCCMA, HadCM3, MIROC e GISS, para o cenário futuro: 2071-2100 e para a estação de primavera. 
estendendo-se para a costa do Chile até os Andes sul peruano e boliviano (Figura 9d).

No modelo GISS houve uma intensificação da APS (Tabela 3), e a área da $\mathrm{BC}$ se localizou sobre o norte do Chile e sul do Peru. O jato subtropical intenso (melhor definido neste modelo) junto com uma área de vorticidade ciclônica, se posicionou sobre os $30^{\circ} \mathrm{S}$. A ZCIT sobre o Atlântico (Pacifico), no período $2071-2100$, acima dos $2^{\circ} \mathrm{N}\left(5^{\circ} \mathrm{S}\right)$ esteve associada com o deslocamento da AAN (APS) para o norte (sul), em relação à sua climatologia (1961-1990), além de observar-se um aumento na convergência de umidade sobre a ZCIT do Atlântico (Figura 9e).

\section{d) Primavera (SON)}

Não se observou um comportamento de chuva característico em todos os modelos. Porém, sobressaem o CCCMA e o HadCM3 por apresentar um padrão contrário ao observado na climatologia 1961-1990, de anomalias positivas e negativas de chuva sobre a Amazônia, respectivamente (Figura 6).

No caso do CCCMA, o campo de circulação em $250 \mathrm{hPa}$ (Figura 10a) mostrou o sistema crista/cavado sobre o centro do continente muito fraco, e no campo de $500 \mathrm{hPa}$ um cavado sobre o Paraguai entre dois núcleos antciclônicos intensos (sobre o sudeste), associado a um campo de divergência em níveis médios e altos $(250 \mathrm{hPa})$. Neste caso, provavelmente os anticiclones não inibem a convecção por subsidência, mas reforçam a convergência de umidade em $850 \mathrm{hPa}$ sobre esta região, o que pode estar causando as anomalias positivas de chuva sobre o Sudeste (Figura 10a). Por outro lado, o HadCM3 mostra uma mudança significativa na circulação em $250 \mathrm{hPa}$, observa-se um anticiclone sobre o Pacifico Sul, próximo a costa do Equador e Peru. A BC mais intensa (Tabela 3) estende-se sobre grande parte do centro do continente, e associa-se com as fortes anomalias positivas de temperatura $\left(8^{\circ} \mathrm{C}\right)$ em superfície, contribuindo com o déficit de chuva sobre a Amazônia (Figura 10c). Todavia, o deslocamento da APS para o sul, ligeiramente mais fraca (Tabela 3), junto com a ZCIT do Pacífico sobre o equador se associam com o excesso de chuva sobre a costa peruana.

O GFDL (Figura 6) mostra a partir da climatologia de 2041-2070, ligeiras anomalias negativas sobre o sul dos Andes peruanos e oeste da Bolívia, que se estendem sobre o sul peruano em 2071-2100. O campo de circulação em $250 \mathrm{hPa}$ (Figura 10c) mostra uma área de forte divergência deslocada para o norte, que atravessa o continente em sentido NW-SE junto com a AB. Ressalta-se também, a intensificação das altas subtropicais (AAS eAPS) em relação à climatologia presente (Tabela 3), mostrando ainda um padrão de inverno (Figura 10c).

O MIROC (Figura 6) gera anomalias negativas de chuva sobre as Guianas que estendem-se sobre o Atlântico, reforçandose em 2071-2100 devido a desintensificação da ZCIT. Por outro lado, sobre o norte da Amazônia gera chuva. No campo de convergência de umidade observa-se um incremento da umidade sobre a Amazônia (Figura 10d), como conseqüência do deslocamento da ZCIT do Pacífico para leste. O sistema $\mathrm{AB} /$ cavado não está definido, embora a zona de convergência de umidade em superfície seja intensa (Figura 10d).

O GISS apresenta na climatologia de 2071-2100 (Figura 6), anomalias positivas de chuva cobrindo grande parte do território peruano, equatoriano, oeste do Amazonas e parte das Guianas. A BC mostra seu núcleo mais intenso (Tabela 3) sobre o sul da Bolívia e o norte da Argentina. Em altos níveis o jato subtropical se desloca para o sul e um núcleo anticiclônico $(\mathrm{AB})$ se forma sobre o Acre (Figura 10d), o que pode favorecer as chuvas sobre essa região.

\section{DISCUSSÃO E CONSIDERAÇÕES FINAIS}

Este trabalho teve como objetivo avaliar as mudanças no padrão de circulação atmosférica sobre a América do Sul, e sua relação com as anomalias de precipitação e temperatura, utilizando cinco modelos climáticos globais acoplados (oceanoatmosfera) derivado do IPCC AR4, para um cenário futuro (A2) com aumento acelerado nas concentrações dos gases de efeito estufa ao longo do século XXI.

Se os modelos climáticos conseguem reproduzir o clima sazonal presente e passado, possivelmente as suas projeções futuras poderão ser menos incertas. Sendo assim, uma consideração inicial a ser feita é que os modelos climáticos ainda não conseguem reproduzir com alto grau de confiabilidade o padrão sazonal que a climatologia observacional apresenta. No entanto, os modelos conseguem simular coerentemente o ciclo anual, apesar dos vieses sistemáticos encontrados. Por esse motivo, se constituem na principal ferramenta de previsão de clima.

Tendo como base essas informações, os resultados aqui encontrados para os cinco modelos do IPCC AR4, também refletem essa problemática. Nenhum modelo simulou o padrão sazonal do clima presente similar ao representado pela Reanálise do NCEP, embora se conheça que a Reanálise não representa o que acontece na realidade. No entanto, em termos gerais as características do escoamento em altos e baixos níveis foram simuladas, sendo que alguns modelos se aproximaram mais ao observado na Reanálise.

Para o clima presente, em termos de precipitação, todos eles apresentaram em maior ou menor proporção a diminuição de chuva sobre a Amazônia e o excesso de chuva sobre os Andes. $\mathrm{Na}$ época de verão e primavera, observou-se que os modelos (a exceção do MIROC) simularam a $\mathrm{AB}$ e a $\mathrm{BC}$ deslocados para o oeste em relação à Reanálise. Especificamente, este deslocamento foi mais diferenciado em superfície com a localização da BC para o noroeste (sobre os Andes do sul do Peru 
e norte do Chile), e com a sua intensidade superestimada pelos cinco modelos do IPCC AR4. Todavia, a Reanálise subestimou a baixa com um núcleo de $1008 \mathrm{hPa}$, sendo que estudos observacionais climatológicos mostram a baixa com um núcleo de $998 \mathrm{hPa}$ (Lichtenstein, 1980; e Seluchi et al., 2003).

$\mathrm{O}$ deslocamento da $\mathrm{BC}$ pode estar relacionado com a dificuldade que os modelos têm em representar a topografia e a fonte de calor. A BC está ligada à convecção sobre a Amazônia, a qual é dificilmente bem simulada pelos modelos numéricos, consequentemente isto também pode afetar a correta localização da BC. No entanto, este é um assunto que precisa ser investigado com mais profundidade em estudos de modelagem, uma vez que alguns dos modelos do IPCC AR4 (HadCM3 e GISS) podem estar simulando uma baixa composta (baixa do Chaco mais a baixa do Noroeste Argentino), devido a sua grande extensão sobre o continente.

O MIROC, embora tenha apresentado um padrão coerente em baixos e altos níveis com a posição da $\mathrm{BC}$ semelhante à Reanálise, este padrão não contribuiu em termos de chuva sazonal, como mostraram as anomalias negativas na Figura 3.

Outra característica comum nos modelos foi a APS mais fraca em todas as estações do ano, o que sugeriu menor subsidência sobre sua área de atuação. Quando localizada ao norte da sua posição climatológica influenciava na localização da ZCIT do Pacífico, deslocando-a também para o norte. Quando a APS se deslocava ao sul da sua posição climatológica, a convecção da ZCIT em $5^{\circ} \mathrm{S}$ era favorecida pela ausência de subsidência, influenciando nas chuvas sobre o norte de Peru e Equador.

Os modelos também apresentaram dificuldades em configurar a ZCAS com um padrão de chuva estendendo-se desde a Amazônia até o sudeste do Brasil. Em geral, os modelos concentraram maior quantidade de chuva ao leste do continente, o que originou em menor ou maior grau, a diminuição de chuva sobre a Amazônia.

Levando em conta o comportamento dos modelos do IPCC AR4 para o clima presente, os cenários futuros mostraram mudanças em seu padrão de circulação, sendo estas mais significativas a partir da climatologia 2041-2070, e se reforçando em 2071-2100. Na estação de verão e primavera, observou-se que a AB continuou deslocada para oeste, inclusive evidenciando-se ligeiramente mais deslocada para oeste e/ou noroeste em relação a sua climatologia (1961-1990). Seguindo este comportamento, a BC (a exceção do MIROC) também continuou deslocada para o noroeste da sua posição climatológica (1961-1990), e no HadCM3 e GISS mostrou-se mais intensa.

Destacam-se neste trabalho os modelos HadCM3 e GISS tanto no comportamento do clima presente como no futuro. $\mathrm{O}$ HadCM3 consegue reproduzir para o clima presente um padrão de circulação mais coerente para o verão e primavera, próximo à
Reanálise, pois configurou melhor a ZCAS, e conseqüentemente subestimou menos a chuva sobre a região da Amazônia. Já para cenários futuros, o padrão se inverte (principalmente no verão e na primavera), e seu padrão de circulação identificou algumas características típicas do El Niño, uma APS fraca e deslocada para o sul, com uma ZCIT do Pacífico ativa sobre os $5^{\circ} \mathrm{S}$, próxima a costa do Equador e norte do Peru, o que se associou as anomalias positivas de chuva sobre estas regiões. Também este modelo simulou déficit de chuva sobre a região do Nordeste e leste da Amazônia, o qual se associou ao deslocamento para o norte do AAN diminuindo a entrada dos ventos alísios úmidos e quentes sobre essa região.

Por outro lado, o GISS, na climatologia presente, foi o que menos se aproximou ao padrão de circulação observado na Reanálise, com uma $\mathrm{AB}$ fracionada em dois núcleos, uma BC muito intensa em relação aos outros modelos, e pouca convergência de umidade. Este comportamento se associou com as anomalias negativas de chuva, especialmente sobre a Amazônia (Figura 2). Para cenários futuros (2071-2100) este modelo gerou excessos de chuva sobre o centro e sul da Amazônia, Belém, e Peru. Na circulação, a $\mathrm{AB}$ continuou fracionada em dois núcleos, porém, o modelo simulou convergência de umidade intensa, o que produz o excesso de chuva.

O modelo GFDL conseguiu simular uma ZCIT sobre os $5^{\circ} \mathrm{S}$ no outono, caracterizando um período chuvoso normal sobre o norte do Nordeste, e isto se associou à posição da AAN e AAS, que favoreceram a sua localização. No entanto, para cenários futuros, o GFDL não mostrou mudanças significativas para a época de chuvas sobre o Nordeste e Norte da Amazônia.

Em relação à temperatura (Figuras não mostradas), todos os modelos sem exceção apontam para um aquecimento. O HadCM3 e o CCCMA são os mais extremos, com anomalias positivas de até $8^{\circ} \mathrm{C}$ sobre o centro do continente, no inverno e na primavera.

É importante relembrar que cenários futuros do clima apenas são projeções de prováveis mudanças que possam vir a acontecer como produto do aumento nas concentrações dos gases de efeito estufa. A possibilidade de que na realidade as emissões evoluam tal como descrita nos cenários é muito remota (Nakicenovic et al., 2000). Por esse motivo, o nível de incerteza nas simulações dos modelos ainda é grande em relação ao que de fato possa acontecer. No que se refere ao modelo, um aprimoramento nas diferentes parametrizações de processos de superfície, convecção, camada limite, topografia, conteúdo de aerossóis e gelo estarão diretamente ligado com uma diminuição das incertezas.

\section{AGRADECIMENTOS}

Este artigo é derivado dos resultados do projeto "FCOUK Global Opportunity Fund-GOF project DCC (Dangerous 
Climate Change) e a UK Hadley Centre", através do sub projeto "Using Regional Climate Change Scenarios for Studies on Vulnerability and Adaptation in Brazil and South America" e do Instituto Nacional de Ciência e Tecnologia INCT - Mudanças Climáticas no CNPq-MCT. Os autores também agradecem ao "Program for Climate Model Diagnosis and Intercomparison" (PCMDI), por disponibilizar as saídas dos modelos do IPCC AR4 no IPCC "Data Archive". Também, se agradece aos revisores anônimos pelas suas valiosas sugestões que contribuíram no aprimoramento do artigo.

\section{REFERÊNCIAS BIBLIOGRÁFICAS}

ACHUTARAO, K.; SPERBER, K. ENSO simulation in coupled ocean-atmosphere models: are the current models better?. Climate Dynamics, v. 27, n. 1, p. 1-15. DOI 10.1007/ s00382-006-0119-7, 2006.

ANDRADE, K.M. Climatologia e comportamento dos sistemas frontais sobre a América do Sul. 2005. $187 \mathrm{f}$. Dissertação (Mestrado em Meteorologia). - Instituto Nacional de Pesquisas Espaciais, São José dos Campos, INPE-14056-TDI/1067, 2005.

BOMBARDI, R. J.; CARVALHO, L. Variability of the monsoon regime over Brazil: the present climate and projections for a $2 \mathrm{xCO} 2$ scenario using the MIROC model. Revista Brasileira de Meteorologia, v.23, n.1, p. 58-72, 2008.

BRANKOVIC, C.; MOLTENI, F. Sensivity of the ECMWF model northern winter climate to model formulation. Climate Dynamics, v. 13, p. 75-101, 1997.

BREUGEM, W.P.; HAZELEGER, A.; J. HAARSMA, J. Multimodel study of tropical Atlantic variability and Change. Geophysical Research Letters, v. 33, L23706, doi:10.1029/2006GL027831, 2006.

CARVALHO, L., JONES, C., LIEBMAN B. The South Atlantic Convergence Zone: Intensity, Form, Persistence, and Relationship with Intraseasonal to Ineranual Activity and Extreme Rainfall. Journal of Climate, v. 17, p. 88-108, 2004.

CAVALCANTI, I. F.; MARENGO, J.; SATYAMURTY, et al. Global Climatological Feature in a simulation using CPTEC/COLA AGCM. Journal of Climate, v. 15, p. 2965-2988, 2002.

COELHO, M.S.; GAN, M. A.;CONFORTE, J. C. Estudo da Variabilidade da posição e da nebulosidade associada à ZCIT no Atlântico, durante a estação chuvosa de 1998 e 1999 no Nordeste do Brasil, 2004. Revista Brasileira de Meteorologia, v. 19, n. 1, p. 23-34, 2004.

DAI, A. Precipitation Characteristics in Eighteen Coupled Climate Models. Journal of Climate, v. 15, p. 4605-4630, 2006. DOTY, B.E. Using the Grid Analysis and Display System Center for Ocean-Land-Atmosphere Interactions
(COLA). University of Maryland, Maryland, Jan 1992.

FIGUEROA, N.F., P. SATYAMURTY e P. L. SILVA DIAS. Simulations of the summer circulation over the South American region with an eta coordinate model. Journal of the Atmospheric Sciences, v. 52, p. 1573-1584, 1995.

GARREAUD, R. D.; FALVEY, M. The coastal winds off western subtropical South America in future climate scenarios. International Journal of Climatology. DOI:10.1002/ joc.1716. 2008.

GRIMM, A. M. and A. NATORI. Climate change and Interanual Variability of precipitation in South America. Geophysical Research Letters, v. 33, L19706, doi10.1029/ 2006GL026821, 2006.

GRIMM, A. M.; SAHAI, A. K.; ROPELEWSKI, C. F. Interdecadal variations in AGCM simulation skills. Journal of Climate, v. 19, p. 3406-3419, 2006.

GUILYARDI, and Coauthors. Unserstanding El Niño in OceanAtmosphere General Circulation Models - Progress and Challenges. Bulletin of the American Meteorological Society, p. 325-340, 2009.

HASTENRATH, S.; HELLER, L. Dynamics of climatic hazard in north-east Brazil. Quarterly Journal of the Royal Meteorological Society, v. 110, n. 4, p. 11-425, 1997.

HUTCHINSON, M.F. Interpolating mean rainfall using thin plate smoothing splines. International Journal of Geographical Information Science, v. 9, n. 4, p. 385-403, 1995. INTERGOVERNMENTAL PANEL ON CLIMATE IPCC: Climate Change 2007: The Physical Science BasisWorking Group I Contribution to the IPCC Fourth Assessment Report. Brussels, February 2007a.

INTERGOVERNMENTAL PANEL ON CLIMATE IPCC: Climate Change 2007: Impacts, Adaptation and Vulnerability-Working Group II Contribution to the IPCC Fourth Assessment Report. Brussels, April $2007 \mathrm{~b}$.

KALNAY, E, ET AL., NCAR 40-year reanalysis project. Bulletin of the American Meteorological Society, v. 77, p. 437-471, 1996.

KODAMA, Y. Large-scale common feature of subtropical precipitation zones (the Baiu frontal zone, the SPCZ and SCAZ) Part 1: Characteristics of subtropical frontal zones. Journal of the Meteorological Society of Japan, v.70, n. 4, p. 813-836, 1992.

LENTERS, J.D.; COOK, K.H. On the origin of the Bolivian high and related circulation features of the South American Climate. Journal of the Atmospheric Sciences, v. 54, p. 656-677, 1997.

LI, J. L.; ZHANG, X. H.; YU, Y.Q.; DAI, F. S. Primary reasoning behind the double ITCZ phenomenon in a coupled ocean-atmosphere general circulation model. Advances in Atmospheric Sciences, v. 21, p. 857-867, 2004. 
LI, W., FU, R.; DICKINSON, R.E. Rainfall and its seasonality over the Amazon in the 21 st century as assessed by the coupled models for the IPCC AR4. Geophysical Research Letters, v. 111, D02111, doi:10.1029/2005JD006355, 2006.

LICHTENSTEIN, E. La depresión del noroeste de Argentina. 1980. 223f. Tesis (Doctorado en Ciencias de la Atmosfera) - Departamento de Ciencias de la Atmósfera. Universidad de Buenos Aires, Buenos Aires, 1980.

LIN, J-L. et al. Tropical Intraseasonal Variability in 14 IPCC AR4 Climate Models. Part I: Convective Signals. Journal of Climate, v. 19, n. 12, p. 2665-2690, 2006.

LIN, B.E. MAPES, ZHANG, M.; NEWMAN, N. Stratiform precipitation, vertical heating profiles, and the MaddenJulian oscillation. Journal of the Atmospheric Sciences, v. 51, p. 296-309. 2004.

LOBO, P.R. Um estudo climatológico da zona de convergência intertropical e sua influencia sobre o nordeste do Brasil. 1982. 93f. Dissertação (Mestrado em Meteorologia). - Instituto Nacional de Pesquisas Espaciais, São José dos Campos. INPE-2534 TDL/101, 1982.

MARENGO, J.A. e coautores. Assesment of regional seasonal rainfall predicatbility using the CPTEC/COLA atmospheric GCM. Climate Dynamics, v. 21, p. 459-475, 2003.

MARENGO, J.; SOARES, W.; SAULO, C.; NICOLINI, M. Climatology of the LLJ east of the Andes as derived from the NCEP reanalyses. Journal of Climate, v. 17, p. 22612280, 2004.

MARENGO, J.A; NOBRE, C., TOMASELLA. J., SAMPAIO, G. DE OLIVEIRA R., CAMARGO, H., OYAMA, M., ALVES. L., BROWN F. The Drougth of Amazonia in 2005. Journal of Climate, v. 21, p. 495-516, 2007 a.

MARENGO, J.A. Mudanças Climáticas Globais e seus Efeitos sobre a Biodiversidade: Caracterização do Clima Atual e Definição das Alterações Climáticas para o Território Brasileiro ao longo do Século XXI. Brasília: Ministério do Meio Ambiente. Série Biodiversidade, v.26, 2007b.

NAKICENOVIC, N., et al. Special Reports on Emission Scenários - SRES, edited by $\mathbf{N}$. Nakicenovic and R. Swart. Cambrigde Univ. Press, New York, 2000.

NEW, M.; HULME, M.; JONES, P. Representing TwentiethCentury Space-Time Climate Variability. Part I: Development of a 1961-1990 Mean Monthly Terrestrial Climatology. Journal of Climate, v. 12, p. 829-856, 1999.

PEZZA, A.; SIMMONDS, I. The first South Atlantic Hurricane: unprecedent blocking, low shear and climate change.
Geophysical Research Letters, v. 32 (L15712), 2005.

RAO, V.B.; HADA, K. Characteristics of rainfall over Brazil: annual variations and connections with southern oscillation. Theoretical and Applied Climatology, v. 42, p. 81-91, 1990. RODWELL, M. J.; HOSKINS, B.J. Subtropical Anticyclones and Summer Monsoons. Journal of Climate, v. 14, p. 3192-3211, 2001.

SALAZAR, L. NOBRE, C.; OYAMA, M. Climate Change consenquences on the biome distribution in tropical South America. Geophysical Research Letters vol. 34, doi:10.1029/2007GLO29695, 2007.

SELUCHI, M.E, SAULO, C., NICOLINI, M. and SATYAMURTY, P. The Northwestern Low: a study of two typical events. Monthly Weather Review, v. 131, p. 2361-2378, 2003.

SERVICIO NACIONAL DE METEOROLOGIA E HIDROLOGIA DE BOLIVIA, SENAMHI, 2007. Boletín Climatológico, Dic-Ene-Feb 2007. Disponível em <http:// www.senamhi.gov.bo/meteorologia/climatologia.php>. Acesso em 10 de nov. 2007.

SERVICIO NACIONAL DE METEOROLOGIA DE ARGENTINA - SNM. Boletín Climatológico, May 2007. Disponível em <http://www.smn.gov.ar/ ?mod=clima\&id=50>. Acesso em 10 de nov. 2007.

STERN, W., MIKAYODA, K. Feasibility of seasonal forecast inferred from multiple GCM simulation. Journal of Climate, v. 8, p. 1071-1085, 1995.

TAKAHASHI, K. and BATTISTI, D. Processes controlling the mean tropical Pacific precipitation pattern: II. The SPCZ and southeast Pacific dry zone. Journal of Climate, v.20, n. 23, p. 5696-5706, 2007.

UVO, C.B. A Zona de Convergência Intertropical (ZCIT) e sua relação com a precipitação da Região Norte do Nordeste Brasileiro. 1989. 99f. Dissertação (Mestrado em meteorologia) - Instituto Nacional de Pesquisas Espaciais, São José dos Campos, (INPE-4887 -TDL/378), 1989.

VALVERDE, M.C., MARENGO, J. Desempenho dos modelos climáticos do IPCC em simular a precipitação presente e futura sobre o território brasileiro. In: XX CONGRESSO BRASILEIRO DE METEOROLOGIA, 2006, Florianópolis, Santa Catarina, 2006. I CD-ROM

VERA, C.; SILVESTRI G.; LIEBMAN, B.; GONZÁLEZ, P. Climate Change scenarios for seasonal precipitation in South America from IPCC AR4 models. Geophysical Research Letters, v. 33, L13707, doi10.1029/2006GL025759, 2006. 